\title{
a-Synuclein and nonhuman primate models of Parkinson's disease
}

\author{
Scott C. Vermilyea ${ }^{a, b}$ and Marina E. Emborga,b,c \\ aNeuroscience Training Program, University of Wisconsin, Madison \\ bWisconsin National Primate Research Center, University of Wisconsin, Madison \\ 'Department of Medical Physics, University of Wisconsin, Madison 1220 Capitol Court, Madison, \\ WI 53715
}

\begin{abstract}
Accumulation of a-synuclein (a-syn) leading to the formation of insoluble intracellular aggregates named Lewy bodies is proposed to have a significant role in Parkinson's disease (PD) pathology. Nonhuman primate (NHP) models of PD have proven essential for understanding the neurobiological basis of the disease and for the preclinical evaluation of first-in-class and invasive therapies. In addition to neurotoxin, aging and intracerebral gene transfer models, a new generation of models using inoculations of a-syn formulations, as well as transgenic methods is emerging. Understanding of their advantages and limitations will be essential when choosing a platform to evaluate a-syn-related pathology and interpreting the test results of new treatments targeting a-syn aggregation. In this review we aim to provide insight on this issue by critically analyzing the differences in endogenous a-syn, as well as a-syn pathology in PD and PD NHP models.
\end{abstract}

\section{Keywords}

Parkinson's disease; alpha synuclein; nonhuman primates; Lewy body; Lewy neurite; animal models

\section{Introduction}

a-Synuclein $\left({\left.\mathrm{a}-\mathrm{syn}^{1}\right)}^{1}\right)$ is a relatively small, 140 amino acid, and 14-kDa presynaptic protein. Current evidence suggests that a-syn is important for normal neuronal function and plays a role in neurotransmitter vesicle release (Bendor et al., 2013). In the presynaptic terminal asyn ensures successful synaptic transmission by shuttling SNARE proteins and interacting

Corresponding author: Marina E. Emborg, M.D. Ph.D., University of Wisconsin, Madison, 1220 Capitol Court, Madison, WI 53715, Ph: 608-262-9714, Fax: 608-263-352, emborg@ primate.wisc.edu.

Publisher's Disclaimer: This is a PDF file of an unedited manuscript that has been accepted for publication. As a service to our customers we are providing this early version of the manuscript. The manuscript will undergo copyediting, typesetting, and review of the resulting proof before it is published in its final citable form. Please note that during the production process errors may be discovered which could affect the content, and all legal disclaimers that apply to the journal pertain.

The authors of this manuscript declare no conflict of interest. 
with synaptobrevin-2 (Chandra et al., 2005). Interestingly, a-syn was originally described in neuropathological conditions. It was first identified as the non-A $\beta$ component (NAC) of amyloid plaques in Alzheimer's disease (Ueda et al., 1993). A few years later, a single point mutation of alanine to threonine in the $53^{\text {rd }}$ (A53T) amino acid residue of the a-syn protein sequence was linked to early onset Parkinson's disease (PD) in an Italian and Greek family with an $85 \%$ penetrance (Polymeropoulos et al., 1997). Since then, other a-syn mutations have been identified in familial PD cases (Kruger et al., 1998; Lesage et al., 2013). Yet the most striking consequence of a-syn identification was the discovery that wild type a-syn is the main component of Lewy bodies (LBs), which are intracytoplasmic eosinophilic aggregates, and Lewy neurites (LNs), which are abnormal filament-containing neurites. Both, LBs and LNs are characteristic pathologies of PD (Spillantini et al., 1998; Spillantini et al., 1997) (Figure 1).

PD is the most prevalent movement disorder and the second most common neurodegenerative disease, after Alzheimer's disease (NINDS). PD affects $1 \%$ of the population over 60 years old; earlier onset has been described mainly in familial cases. The cause of PD is still unknown, although old age, environmental toxins and genetics are known risk factors. With respect to the latter, several mutations including LRRK2, PINK1, DJ-1 in addition of SNCA, have been linked to PD (Puschmann, 2013).

First described in 1817 by James Parkinson, PD is typically diagnosed by motor signs such as bradykinesia, resting tremor, postural instability, and a characteristic hunched-over posture. Today PD is considered a multisystem disorder as it also presents numerous secondary motor as well as non-motor symptoms including a diminished sense of smell, dysphagia, REM sleep behavior disorder, autonomic dysfunction, and depression (Chaudhuri and Odin, 2010; Chaudhuri et al., 2011; Langston, 2006). These symptoms may precede primary motor signs and are proposed as prodromal symptoms of PD (Postuma et al., 2012). The pathological hallmark of PD is the loss of mesencephalic melanin-pigmented dopaminergic neurons in the substantia nigra pars compacta ( $\mathrm{SNpc}$ ) and the presence of $\mathrm{LBs}$ and LNs (described above); primary motor symptoms are related to nigral pathology. By the time the disease has manifested to the point of clinical detection and diagnoses, around 50\% of dopaminergic (DA) neurons are lost from the SNpc. Secondary motor as well as nonmotor symptoms are associated with neurodegeneration and a-syn positive LBs in several areas of the CNS and PNS, including the locus coeruleus, and autonomic nervous system (Braak et al., 1995; Braak et al., 2004; Seidel et al., 2014).

Current PD treatments are mainly symptomatic; none have yet been proven to be neuroprotective (Stocchi and Olanow, 2013). New ideas regarding PD etiology and possible treatments are emerging based on advances in our understanding of the role of a-syn in PD

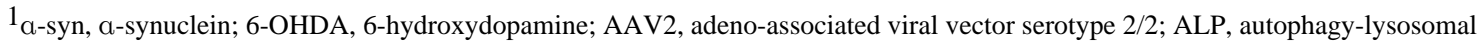
pathway; BBB, blood brain barrier; c-hGH, cadaver-derived human growth hormone; CK, casein kinases; DA, dopamine; DAT, dopamine acetyltransferase; DLB, disease with Lewy bodies; ECFP, enhance cyan fluorescent protein; EPM1, progressive myoclonus epilepsy type 1; GFP, green fluorescent protein; GRKs, G-protein-coupled receptor kinases; IVF, in vitro fertilization; LB, Lewy body; LN, Lewy neurite; LV, lentivirus; MAO-B, monoamine oxidase-B; MAP, microtubule-associated protein; MPTP, 1-methyl-4phenyl-1,2,3,6-tetrahydropyridine; NAC, non-A $\beta$ component; NHP, nonhuman primate; PD, Parkinson's disease; PFF, preformed fibril; PK, proteinase K; PLKs, polo-like kinases; ROS, reactive oxygen species; sgRNA, single guide RNA; SN, substantia nigra; SNpc, substantia nigra pars compacta; TH, tyrosine hydroxylase; UCH-L1, ubiquitin carboxy-terminal hydrolase L1; UPS, ubiquitinproteasome system; WT, wild type.
} 
(Chu and Kordower, 2015; Kalia and Lang, 2015; Shannon et al., 2012; Xilouri et al., 2013). Nonhuman primate (NHP) models of PD have proven essential for understanding the neurobiological basis of the disease and for the preclinical evaluation of first-in-class and invasive therapies. In addition to neurotoxin, aging and intracerebral gene transfer models, a new generation of models using inoculations of a-syn formulations, as well as transgenic methods is emerging. Understanding of their advantages and limitations will be essential when choosing a platform to evaluate a-syn-related pathology and interpreting the test results of new treatments targeting a-syn aggregation. In this review we aim to provide insight on this issue by critically analyzing the differences in endogenous a-syn, as well as a-syn pathology in PD and PD NHP models.

\section{2. a-Synuclein in normal conditions}

\subsection{Normal a-syn in humans}

In humans, a-syn is encoded from the SNCA gene on chromosome 4. Structurally, beginning near the $\mathrm{N}$-terminus, the protein sequence has six imperfect hexameric KTKEGV repeats. These hexameric repeats are believed to be responsible for the formation of an alpha-helical secondary structure (Bartels et al., 2011), which reacts with various intracellular membrane proteins. Bartels and colleagues also observed in vitro that wild type (wt) human a-syn proteins could form stable non-aggregating soluble tetramers. a-Syn expression has not been typically investigated in normal healthy patients. Chu and Kordower (2007) analyzed age-related changes in a-syn optical density within nigral neurons and found that in aged individuals a-syn was more abundant that in young and middle aged cases. Intracytoplasmic nigral $\alpha$-syn increases, but not $\beta$-syn, strongly correlated with decreases in TH expression (Chu and Kordower, 2007).

\subsection{Normal a-syn in NHPs}

Similar to humans, a-syn is ubiquitously expressed in the central and peripheral nervous system of NHPs (Figure 2). The a-syn protein sequence is well conserved among mammalian species and most vertebrates (Figure 3). Gorilla (G. gorilla), orangutan (Pongo), and bonobo ( $P$. paniscus) have exact copies of the human protein sequence, while Old World monkeys have altered residues at different sites such as 95 and 114 in rhesus $(M$. mulatta) and patas monkeys (E. patas), and only 114 in cynomologous (M. fascicularis). New World NHPs, like squirrel monkeys (S. sciureus) have altered residues at sites 87, 99, and 103, while common marmosets (C. jacchus) have differences in 53, 87, 99, and 103. The a-syn protein sequence in mouse lemur (M. murinus) is not currently available. Interestingly, most New World monkeys, including the common marmoset, white-lipped tamarin (S. labiatus) and spider monkey (A. geoffroyi), as well as most all other vertebrates naturally have a threonine at the $53^{\text {rd }}$ residue of the a-syn sequence, compared to humans, apes and Old World primates which have alanine in the $53^{\text {rd }}$ residue (Hamilton, 2004). Similar to humans, a-syn expression in NHPs is typically localized to the pre-synaptic terminal and under normal conditions does not aggregate or fibrillize. 


\section{Pathological post-translational modifications and mutations of a-syn}

a-Syn is prone to various post-translational modifications, including ubiquination, crosslinking, truncation, oxidation, and phosphorylation (Oueslati et al., 2010). In its normal functioning state, $a$-syn is soluble within the cytoplasm of neural presynaptic terminals. It may become phosphorylated, accumulate, and begin forming insoluble aggregates that cannot be metabolized by autophagy or proteasome cellular pathways. It is unclear in what order these events occur, however when aggregates are formed, they can be visualized within dystrophic neurites or the soma of cells. Insoluble a-syn can be distinguished immunohistochemically using proteinase $\mathrm{K}$ (PK) digestion. PK will abolish any soluble asyn labeling, by leaving only insoluble PK resistant aggregates behind. It has been observed that with just a single amino acid mutation on the human a-syn protein, insoluble aggregates can be formed (Giasson et al., 1999; Narhi et al., 1999).

\subsection{Abnormal post-translational modifications of a-syn}

As it is seen with other neurodegenerative diseases (Medina and Avila, 2014; Watkin et al., 2014), abnormal protein phosphorylation is thought to play an important role in PD pathology. The C-terminus end of a-syn contains various serine and tyrosine loci capable of being phosphorylated. Serine 129 (S129) is of particular interest in regards to the intracellular insoluble a-syn aggregates. Patients with dementia with Lewy bodies (DLB) have over $90 \%$ of urea soluble a-syn phosphorylated at S129, compared to normal rat brains that have only 4\% of S129 phosphorylated (Fujiwara et al., 2002). In normal human patients, levels of S129 phosphorylation are minute (Paleologou et al., 2010). S129A mutant rats that are unable to phosphorylate have decreased formation of inclusions in transfected cells (Smith et al., 2005).

It is not clear if a-syn hyper-phosphorylation leads to its aggregation, eventual toxicity and neural cell death (Fujiwara et al., 2002) or if hyper-phosphorylation is a consequence of asyn aggregation. Interestingly, when HEK-293T cells transfected to produce wt a-syn were treated with recombinant 21-140 a-syn fibrils, both soluble and fibrillized forms of a-syn were substrate for G-protein-coupled receptor kinases (GRKs), casein kinases (CK) 1 and 2, or polo-like kinases (PLKs) 1-3 at S129 (Waxman and Giasson, 2011). CK2 and the PLKs were associated with phosphorylation of soluble S129, while PLKs and possibly other uncharacterized kinases were involved with aggregated a-syn phosphorylation (Waxman and Giasson, 2011).

\section{2. a-Syn mutations linked to PD}

As mentioned in the introduction, specific mutations in the SNCA gene, including A30P, E46K, G51D, and A53T, as well as SNCA multiplications, have been associated with increased a-syn aggregation.

The most studied a-syn mutations linked to familial PD are the A53T, found in at least 12 families of Greek, Korean and Swedish origin, and the A30P variant, found in a German family. In addition, two other mutant $a$-syn sequences have been directly related to the onset of PD in human families, one being the G188A/E46K mutation from a Spanish family 
(Zarranz et al., 2004), and more recently the G51D mutation found in 4 individuals from a French family that suffer from parkinsonian-pyramidal syndrome (Lesage et al., 2013).

The DNA alteration that leads to replacement of the amino acid alanine by threonine at the $53^{\text {rd }}$ residue (A53T) is the result of a genomic missense mutation of the nucleotides guanine to adenine at the $209^{\text {th }}$ genomic locus (G209A). In humans, the A53T mutation leads to a disruption of the alpha-helical conformation. An erroneous kink in the protein may facilitate the formation of beta-sheet organizations among multiple mutant a-syn proteins (Polymeropoulos et al., 1997). It has also been described that the N- and C-termini of the A53T mutant a-syn protein are less accessible in the LB filaments. This would imply that the ends of the protein might be responsible for the polymerization and fibrilization of the proteins (Giasson et al., 1999).

PD onset in patients carrying the A53T mutation is usually between 30-50 years of age, much earlier than idiopathic PD, which is typically observed past 60 years of age. As we mentioned above, PD pathology is not observed in other vertebrates that naturally have the T53 residue. It has been hypothesized that PD associated with A53T mutation is due to humans' extended life span. Yet vertebrate species with long life spans, including the elephant, Baltic sturgeon, European catfish, common carp, and Galapagos tortoise, which naturally have a threonine in the $53^{\text {rd }}$ residue, do not present PD-like LB pathology (Larsen et al., 2009). An alternative explanation is that a-syn expression levels may be diminished in these species, preventing the accumulation and subsequent aggregation of the protein.

The A30P mutant a-syn protein stems from a genomic G88C missense mutation (Kruger et al., 1998). Evidence suggests that the A30P mutation may not be as prone as the A53T mutation to induce self-aggregation. Experiments looking at the lag time for the formation of insoluble protein aggregates and fibrilization have shown that the $\mathrm{A} 30 \mathrm{P}$, compared to A53T mutated a-syn, aggregates more slowly and that both aggregate sooner than wild type human a-syn (Giasson et al., 1999; Narhi et al., 1999), although the latter needs further evaluation (Conway et al., 2000).

SNCA multiplication is another gene variant. It was first found as a SNCA triplication in a family with autosomal dominant PD with an average disease onset of 34 years of age (Singleton et al., 2003). SNCA triplication results in an early onset, aggressive and fully penetrant form of PD.

\subsection{Protein clearance pathways and a-syn}

The ubiquitin-proteasome system (UPS) and the autophagy-lysosomal pathway (ALP) are responsible for cellular protein clearance (Ebrahimi-Fakhari et al., 2011; Goldberg, 2003; Klionsky, 2007). Under normal conditions, UPS seems to be the main process for a-syn degradation. ALP is more critical when the cell has a high burden of a-syn expression (Ebrahimi-Fakhari et al., 2011). In addition, it has been argued that ubiquitination of a-syn affects the clearance pathway (Rott et al., 2011) with monoubiquitinated a-syn mostly metabolized by UPS and deubiquitinated $a$-syn cleared by ALP. 
It is still unclear in PD whether a-syn accumulation affects UPS or ALP, or it is a consequence of dysfunction in the protein clearance pathways. Administration of proteasome inhibitors (e.g.: PSI (Z-Ileu-Glu(OtBu)-Ala-Leu-CHO) or epoxomicin) has been proposed to model PD in animals (McNaught et al., 2004) yet the results were inconsistent (Bove et al., 2006; Kordower et al., 2006). It has been suggested that mutations in parkin and the ubiquitin carboxy-terminal hydrolase L1 (UCH-L1) observed in familial PD result in a direct disruption of the UPS (Leroy et al., 1998; McNaught et al., 2003; Shimura et al., 2001). Overexpression of a-syn in vitro has been shown to disrupt or inhibit the autophagy pathway (Winslow et al., 2010). Interestingly, this interference was only observed in vitro with wt a-syn, not the A53T or A30P overexpression in a human cervical carcinoma cell (HeLa)-derived reporter cell line. However, the A53T mutation had been previously implicated in the disruption of ALP in PC12 cells in vitro (Stefanis et al., 2001).

\subsection{Lewy bodies (LBs) and Lewy neurites (LNs)}

As we mentioned before, in PD LBs are found in the SNpc, as well as other areas of the central and peripheral nervous system (Braak et al., 1995; Braak et al., 2004; Seidel et al., 2014). LBs are known to have a-syn but over 70 different types of proteins have also been identified, a few of which include ubiquitin, neurofilament, microtubule-associated protein (MAP) 1B, synphilin-1, tau, and parkin (Wakabayashi et al., 2007). A PD diagnosis is typically confirmed post-mortem by the existence of LBs combined with nigral cell loss. aSyn is the major component of LBs in both familial and idiopathic PD, as well as dementia with LBs (DLB) (Spillantini et al., 1998; Wakabayashi et al., 2007).

In normal conditions a-Syn can be found free and soluble in the cytoplasm or bound to the intracellular aspect of the lipid bilayer (McLean et al., 2000; Spillantini et al., 1997). LB formation is proposed to start with abnormal accumulation of a-syn in the neuronal cytoplasm (Wakabayashi et al., 2007), later on forming 'pale bodies' which are irregularly dense aggregates. The pale body then develops into the stereotypical dense peripheral 'membrane' and translucent core structure characteristic of LBs.

PD patients have abnormal aggregates of a-syn in $10 \%$ of their surviving pigmented nigral neurons (Mori et al., 2006). Due to the variety of proteins found in a LB, it has been controversial whether LB formation may be the result of, or a compensatory mechanism to cope with aggregated a-syn and ubiquitin not metabolized by autophagy or proteasome pathways, which ultimately may contribute to a progressive, cytotoxic process (Dauer and Przedborski, 2003).

Interestingly, LBs were found in fetal mesencephalic neurons grafted into the striatum of PD patients over 10 years before death which suggested that a-syn can be transferred from neuron to neuron, in this case from host to graft (Cooper et al., 2009; Kordower et al., 2008; $\mathrm{Li}$ et al., 2008; Li et al., 2010). The prion hypothesis for PD, in which a-syn has a key role for spreading the disease across the nervous system following Braak's prediction emerged from this finding (Braak et al., 2004; Chu and Kordower, 2015; Hallett et al., 2014; Hilker et al., 2011; Mendez et al., 2008). Although exciting, the prion hypothesis is controversial and several valid issues contradict its feasibility. First, compared to prion protein diseases, like Creutzfeld-Jakob disease, PD lacks infectiousness (Hilker et al., 2011). Second, prion 
diseases are often latent, followed by a rampant and quickly deteriorating manifestation. This is in stark contrast to the slow progressive nature of PD pathology. Lastly, while recipients of cadaver-derived human growth hormone (c-hGH) present higher risk of developing prion disease, investigations failed to identify increase risk of PD in this patient population (Irwin et al., 2013).

\section{4. a-Syn expression in NHP models of PD}

NHP PD models have been based on known risk factors of the disease, such as aging, exposure to environmental neurotoxins and genetics (by viral vector transfer of PDassociated genes) (Emborg, 2007). Evidence that a-syn and LBs may have a role for initiating and spreading PD pathology has stimulated the development of new models based on inoculation of a-syn and LBs formulations. In this section we will examine a-syn changes in NHP models.

\subsection{Aging}

Aged NHPs, like aged humans, present loss of dopaminergic nigrostriatal function and have been proposed as models of early PD (Emborg and Kordower, 2002; Emborg et al., 1998). The definition of an aged monkey depends on the species. Rhesus monkeys are considered aged when they are postmenopausal and older than 23 years (Chu and Kordower, 2007). Examples of other aged primates are: 8 years for the mouse lemur (Canron et al., 2012), 10 years for the common marmoset (Ridley et al., 2006), 15 years for the squirrel monkey (Forno et al., 1986) and 18 years for the baboon (Tran and Greenwood-Van Meerveld, 2014).

Nigral a-syn expression in normal humans was reported to increase with age, particularly in the neuronal cell body, without affecting the total number of nigral neurons (Chu and Kordower, 2007). Similarly, endogenous nigral a-syn expression in rhesus monkeys seems to be higher among older animals (Chu and Kordower, 2007). Quantification of a-syn optical density in nigral neurons showed increases of $169 \%$ in middle-aged (15-23 years) and $215 \%$ in aged (24-34.1 years) monkeys compared to young (2-12.1 years) rhesus. Interestingly, tyrosine hydroxylase $(\mathrm{TH})$ immunostaining negatively correlated with a-syn expression. PK treatment cleared a-syn immunostaining, suggesting that a-syn accumulation in the aged primate brain is soluble, not aggregated. Changes in phosphorylated S129 and nitrated a-syn have not been reported.

Compared to rhesus, Microcebus murinus (mouse lemur) seems to present more dramatic changes in a-syn expression with older age. Proteinase $\mathrm{K}$ resistant phosphorylated a-syn aggregates were observed in the SN, striatum, anterior olfactory nucleus, and cortex of only the aged animals (Canron et al., 2012). Phosphorylated S129 and nitrated a-syn were also present suggesting post-translational modifications associated with aging.

\subsection{Neurotoxins}

6-hydroxydopamine (6-OHDA) and 1-methyl-4-phenyl-1,2,3,6-tetrahydropyridine (MPTP) are the most used neurotoxins to model PD in NHPs. 
4.2.1 6-OHDA-6-OHDA (Senoh, 1959) is a catecholaminergic neurotoxin widely used to induce dopaminergic nigral cell death in rodents and marmoset monkeys (Blandini et al., 2008; Eslamboli et al., 2005; Ungerstedt, 1968). It does not cross the blood brain barrier (BBB) and to induce central effects 6-OHDA is stereotaxically injected directly into the brain region of interest. It is then selectively taken up by catecholaminergic neurons through monoamine transporters, inducing sympathetic neuronal loss by increasing the production of reactive oxygen species (ROS), and disrupting energy metabolism and neuronal activity (Blum et al., 2001). Intracerebral 6-OHDA dosing to rodents leads to nigral cell loss without inducing PD-like changes in a-syn expression (Decressac et al., 2012), although studies in a-syn gene knockout mice suggest that its toxicity is partially associated with a-syn (Alvarez-Fischer et al., 2008).

Information about 6-OHDA and a-syn expression in NHPs is limited. In common marmoset monkeys 6-OHDA injections into the nigrostriatal bundle or the striatum leads to typical parkinsonian motor deficits associated with loss of nigral TH positive cells (about 63\%); no report on a-syn expression is available (Eslamboli et al., 2005). Although in rhesus 6-

OHDA is rarely used intracerebrally, it can be administered systemically to model cardiac dysautonomia, a common PD nonmotor symptom (Joers and Emborg, 2014). In these animals intravenous dosing of 6-OHDA induces loss of cardiac catecholaminergic innervation and decreased levels of circulating catecholamines (Joers et al., 2014a; Joers et al., 2012). The cardiac nerve loss is associated with decreased expression of soluble a-syn; LB or PK resistant a-syn aggregates are not observed. Although systemic dosing of 6OHDA has some central effects, nigral a-syn expression does not seem to be affected (Joers et al., 2014b).

4.2.2 MPTP—PD models in mice and NHPs are usually induced by MPTP intoxication (Fox and Brotchie, 2010). This dopaminergic neurotoxin can cross the BBB and is administered to NHPs via s.c., i.m., i.v. or internal carotid artery injection. Severity of the PD syndrome depends on route, dose and frequency of administration; dosing regime varies between species (Emborg, 2007). In the brain MPTP is transformed into its toxic metabolite $\mathrm{MPP}^{+}$by monoamine oxidase-B (MAO-B). $\mathrm{MPP}^{+}$is then selectively taken up by the DA transporter into dopaminergic neurons where it disrupts normal mitochondrial respiration by acting as a mitochondrial complex I inhibitor, leading to oxidative stress and apoptosis (Przedborski and Vila, 2001). MPTP parkinsongenic effects are known today because of its identification as the cause of a rapid onset PD-like syndrome in drug-addicted patients who self-administered meperidine contaminated with the neurotoxin (Davis et al., 1979; Langston et al., 1983). The first report of a MPTP case, corresponding to a 23 year old man with a survival time post MPTP of 18 months described severe nigral cell loss and one typical nigral LB observed with $\mathrm{H} \& \mathrm{E}$ as a 'homogenous intracytoplasmic inclusion with a peripheral halo' (Davis et al., 1979). A later publication on the postmortem analysis of 3 MPTP-exposed cases, 41-42 years old and survival times after MPTP ranging from 3-16 years also documented severe nigrostriatal dopaminergic loss, plus the presence of active gliosis in the nigra (Langston et al., 1999). One of the three patients, had a few dystrophic neurites but intracellular inclusions or LBs were not observed with H\&E or antibodies against a-syn, ubiquitin and tau; accounts of the other two cases did not include a 
description of immunohistochemistry against a-syn, ubiquitin and tau (Langston et al., 1999).

In mice, MPTP intoxication induces nigral cell loss while a-syn expression seems to change depending on the dosing regimen. Temporary a-syn accumulation in nigral neurons was observed during the first 4 days post subacute MPTP administration $(30 \mathrm{mg} / \mathrm{kg} /$ day i.p. $\times 5$ days) (Vila et al., 2000). Moreover, mice treated for 21 days with continuous low dose of MPTP via an osmotic minipump presented nigral inclusions immunoreactive for ubiquitin and a-syn (Fornai et al., 2005), although it is not clear if the aggregates were insoluble. The mice also showed progressive behavioral deficits, long lasting activation of glucose uptake and inhibition of the ubiquitin-proteasome system. Continuous MPTP administration to asyn-deficient mice also induced metabolic activation, but behavioral symptoms, neuronal cell death, number of aggregates as well as inhibition of the ubiquitin-proteasome system were reduced, suggesting that continuous low-level exposure to MPTP elicits toxicity that is a-syn-dependent. Interestingly, chronic low dosing with the pesticide rotenone, which also causes nigral cell loss by mitochondrial complex I inhibition, induces cytoplasmic fibrillary inclusions containing ubiquitin and a- syn (Betarbet et al., 2000; Klein et al., 2011; PanMontojo et al., 2010; Pan-Montojo et al., 2012; Sherer et al., 2003). These rodent reports provide evidence that mitochondrial dysfunction triggers protein accumulation, and imply that a-syn aggregation may be time-dependent, requiring persistent metabolic alterations.

Studies in squirrel monkeys suggest that aging may facilitate a-syn aggregation after MPTP intoxication. Eosinophilic inclusions in the cell bodies and processes of neurons located in the SN, dorsal motor nucleus of the vagus, nucleus basalis of Meynert, and dorsal raphe nucleus were described in an aged squirrel monkey (15-20 years old) treated with MPTP (1 $\mathrm{mg} / \mathrm{kg}$ i.p. twice per day for 5 days) and necropsied 16 days after dosing (Forno et al., 1986). A follow up study in animals over the age of 12 (Purisai et al., 2005) treated with a single dose of MPTP $(1.75 \mathrm{mg} / \mathrm{kg}$, s.c.) showed nigral cell loss of $10 \%$ at 1 week and $40 \%$ at 1 month with increases in a-syn mRNA and protein. At one week a-syn immunoreactivity was evident at the level of neuronal fibers but not nigral cell bodies, while at one month $80 \%$ of surviving neurons were positive. Further immunohistochemistry and immunoelectron microscopy analysis of animals $(n=7)$ MPTP-treated with a similar paradigm and necropsied one month later found $a-s y n$ accumulation in nigral cell bodies and dystrophic axons positive for $\mathrm{a}$-syn. Both, cell bodies and dystrophic axons, were positive for nitrated and phosphorylated a-syn, while a subset of these axons also had PK resistant a-syn aggregates, which suggests the development overtime of PD-like LB pathology (McCormack et al., 2008).

MPTP effects on a-syn were also observed in adult old world monkeys. In baboons, MPTP dosing $\left(0.4 \mathrm{mg} / \mathrm{kg}\right.$ i.m. for 6 days and $0.27 \mathrm{mg} / \mathrm{kg}$ on the $7^{\text {th }}$ day, necropsy 10 days later) induced redistribution of nigral a-syn from the axon terminal to the cell body and dendrites, described as aggregates that could be in the process of becoming LBs (Kowall et al., 2000). In cynomolgus monkeys chronic and prolonged MPTP administration (12-14 injections, 0.3 $\mathrm{mg} / \mathrm{kg}$, i.v., intermittently for two years beginning at age 2 and sacrificed 10 years later), induced accumulation of a-syn and phosphorylated a-syn immunoreactivity in the few 
remaining nigral neuronal cell bodies and punctate structures in the neuropil. Punctate ubiquitin staining was also found but not typical LBs (Halliday et al., 2009).

\subsection{Viral vector transfer of PD-associated genes}

Viral vector gene transfer methods are currently used to overexpress specific SNCA mutations in order to assess their impact in nigral cell neurodegeneration and PD onset. Gene transfer has been done by direct intracerebral injection into the SN of adult monkeys, as well as by injection into oocytes before fertilization to induce transgenesis.

4.3.1. Intracerebral viral vector gene transfer-Intracerebral viral vector transfer of PD-related genes is proposed as a shortcut to model PD caused by genetic mutations. The feasibility of this concept has been first demonstrated in rats, which after intracerebral delivery of adeno-associated viral vector serotype 2/2 (AAV2) encoding for human wild type or A53T a-syn to the SN present progressive nigral dopaminergic cell loss and intracellular accumulation of a-syn protein (Decressac et al., 2012; Kirik et al., 2002; Koprich et al., 2010; Lindgren et al., 2012).

In NHPs, two peer-reviewed reports in common marmoset monkeys have been published. In the first one (Kirik et al., 2003), the animals received intranigral injections of AAV2 encoding for either human wild type ( $w t ; n=2)$ or A53T mutated a-syn ( $n-2)$ and showed by 16 weeks 30-60\% loss of nigral dopaminergic neurons compared to AAV-Green Fluorescent Protein (GFP) treated monkeys $(n=4)$. Ninety to $95 \%$ of surviving nigral cells had a-syn positive cytoplasmic inclusions, swollen and dystrophic neurites and granular deposits. In a follow up study by the same group (Eslamboli et al., 2007) the authors described the onset of motor symptoms 2 weeks post AAV2-wt and A53T treatments, which they attributed to protein buildup overtime. This effect seems to be slower in the marmoset than rodents (Bjorklund et al., 2000; Burger et al., 2004), probably due to species variation of transfection levels and size of the brain area affected. Only 2 of the 8 AAV2-wt treated monkeys show SN cell loss (35 and 45\%, respectively) but was not significant compared to AAV-GFP animals $(n=10)$. In contrast, 6 of 7 AAV-A53T animals displayed greater than $40 \%$ nigral cell loss on the side of the injection and was significant compared to both the rAAV-wt and rAAV-GFP injected animals. This suggests the two a-syn proteins produce different levels of toxicity. Although overexpression of both genes induces a-syn aggregation, A53T overexpression induced greater aggregation demonstrated by increasing time of proteinase $\mathrm{K}$ digestion and more dystrophic neurites. Colocalization of TH and asyn immunoreactivity revealed intracellular aggregates in axonal and dendritic striatal projections of nigral dopaminergic neurons. Interestingly, ubiquitin-containing aggregates were also observed in the SN.

More recently, Yang and colleagues (Yang et al., 2015) evaluated in rhesus the effect of intracerebral mutated a-syn gene transfer and age. The authors first tested a lentiviral vector injection encoding for A53T in one animal and compare it to a saline treated subject and found small neuritic aggregates. Based on this finding, animals received a unilateral nigral injection of lentiviral vectors encoding for GFP ( 8 years old, $\mathrm{n}=1$ ) or A53T ( 2 years old, $\mathrm{n}=1 ; 8$ years old, $\mathrm{n}=1 ; 22$ years, $\mathrm{n}=1)$. After 8 weeks post surgery the authors found that 
animals with A53T injections had LNs that were more abundant in the older animals. The authors compared pathologies between the 8-year-old monkey and 10 months old mice (also treated with lentiviral vectors encoding for A53T) and concluded that monkeys are more vulnerable to A53T-induced neurodegeneration and pathology.

4.3.2. Transgenic PD models by viral vector gene delivery-The generation of a transgenic NHP PD model aims to create a systemic, progressive PD model. One way this has been achieved is by lentiviral vector delivery of genes encoding human A53T a-syn to MII stage rhesus monkey oocytes prior to fertilization, followed by in vitro fertilization (IVF) and implantation (Niu et al., 2014a). Out of 75 implantations to 25 different surrogates, 6 successfully infected transgenic animals have been generated. Interestingly, in a pair of transgenic and control stillborn monkeys, the authors were able to compare A53T a-syn expression. They determined that the A53T expressing monkey had elevated levels of a-syn in the cell bodies of neurons within the SN, striatum, and cortex. However, no phosphorylated S129 was observed, and no LBs were found. In surviving transgenic monkeys ( $n=6 ; 3$ of which were too young for training), behavioral abnormalities have begun to arise by 1.5 and 2.5 years of age. The single older monkey ( 2.5 yo) exhibited a decrease in cognitive function as measured by a recognition test. This same monkey also had an increased frequency and duration of walking in circles, which was interpreted as a sign of anxiety. All 3 A53T monkeys had difficulty in a finger coordination and dexterity test compared to controls. These findings suggest that transgenic overexpression of human A53T a-syn may induce progressive symptoms that resemble PD.

\subsection{Inoculation of a-syn preformed fibrils or LBs extracts}

Novel animal models of PD are emerging from testing a-syn pathogenesis by inoculation of a-syn preformed fibrils (PFFs) or LBs extracts. Exposure to exogenous PFFs (from human or mice origin) seeded the formation of LB-like aggregates in cultures of cells overexpressing a-syn (Luk et al., 2009) or primary neuronal cultures (Volpicelli-Daley et al., 2011). The aggregates developed within 2 weeks post exposure and were also ubiquitin positive, intracerebral striatal injections of PFFs in mice also generated LBs and LNs (Luk et al., 2012). The intracellular aggregates were distributed from the injection site along neural networks. At 30 days post surgery aggregates were found in the SN, and by 180 days they were associated with significant of loss of nigral dopaminergic neurons and motor deficits. At this moment peer-review reports in NHP PFF models are not available, although a conference abstract (Kordower et al., 2014) suggests that in rhesus PFFs putaminal inoculation may also induce LB aggregates in the nigrostriatal axis.

As an alternative method to assess a-syn-induced aggregation, investigators have tested the effect of intracerebral injections of nigral-LB enriched fractions purified from 3 postmortem PD brains (Recasens et al., 2014). In wild type C57/BL6 mice an injection above the SN of LB-extracts triggered LB-like pathology in the neural network and was associated with dopaminergic nigrostriatal neurodegeneration. These pathological changes were not observed in a-syn deficient C57B16Sv129 mice or in wild type mice that received LB fractions without a-syn. As part of the same report, macaque monkeys (not clear if rhesus or cynomolgus) received two LB-extract inoculations in the 'motor striatum' $(\mathrm{n}=2)$ or one 
injection in the $\mathrm{SN}(\mathrm{n}=2)$. One of each set of treated monkeys received MPTP dosing 3 years earlier. Analysis of inoculation effects where compared to MPTP-treated or untreated monkeys. Moderate loss of striatal C11 DTBZ uptake (approximately 34\%) assessed by PET was found at 9 months in the striatal injected monkey and at 12 months in the nigral one; no motor symptoms were observed in either animal. Postmortem analysis 14 months later showed mild to moderate nigral cell loss (40\% and 15\% loss) and increased expression of asyn (soluble) in the injection site and related network areas, without definitive LB formation. It is not clear if the previous treatment with MPTP had an effect on a-syn-related pathology.

\section{Discussion}

During our analysis of a-syn in currently available NHP models, several issues arose that challenge our current understanding of the role of this protein in PD pathology. They include questions regarding incidence of naturally occurring PD in monkeys, impact of a-syn mutations in PD development and normal vs. increased a-syn expression in NHPs.

\subsection{If a-syn is conserved across primate species, why are reports of naturally occurring PD monkeys missing?}

As we discussed in the aged monkey section, new and old world NHPs present age-related nigrostriatal dysfunction. In addition, rhesus monkeys have intracellular translocation of asyn protein with age. These changes are similar to human ones and suggest that in primates, a-syn aggregation and related pathology may be facilitated with age. Yet, reports of spontaneous PD in NHPs with postmortem confirmed diagnoses by LB identification are not currently available. Lack of PD in NHPs may be due to species resistance to develop the disease or, simply, it has not been detected. If we consider PD incidence in the human population is 1 for 100 persons over 60 years old (de Lau and Breteler, 2006), our chances to detect PD in captive rhesus and other monkey colonies are limited. Colonies of aged rhesus monkeys are rare due to the intensive care required and the high cost of maintaining animals for several decades. For example, in the past we have found one aged rhesus monkey ( 28 yrs old) with PD-like symptoms and significant loss of TH and dopamine transporter (DAT) positive neurons (Emborg et al., 1998) yet at the time a-syn antibodies for immunohistochemistry were not readily available and as we did not systemically search for presence of LBs, we probably missed an opportunity to identify a PD case.

\subsection{If the A53T mutation is associated with early PD, why do 53T-carrying species not present PD?}

Presence of threonine in the $53^{\text {rd }}$ amino acid location of the a-syn protein is naturally occurring in marmoset monkeys and other vertebrates, yet in human subjects A53T is a missense mutation associated with aggressive and early onset PD. Interestingly, in addition to the 53T, the common marmoset has only three other variations in the a-syn protein: S87N, Q99H, and N103S, while rodents have 7 total amino acid differences from the human. In this context, it seems that A53T mutated a-syn is not necessarily toxic and rather that a combination of events, or downstream activation of species-specific genes is needed to induce PD. 


\subsection{Does a-syn expression change after environmental insults?}

If a-syn has a role in PD-induced neurodegeneration, exposure to environmental toxins, which has been identified as a risk factor for PD (Priyadarshi et al., 2001) should trigger changes in a-syn, ideally inducing LBs. In humans, MPTP intoxication induced a PD-like syndrome associated to loss of dopaminergic nigral cell, yet a LB was only found in one patient (Davis et al., 1979). Rodent studies using chronic dosing of rotenone or continuous MPTP dosing, have identified a-syn aggregates, although stereotypical LBs were not observed. Similar to rodents, stereotypical LBs have not been found in MPTP-treated monkeys, yet changes in a-syn expression, including accumulation, aggregation and translocation, were reported.

Interestingly, when the reports in human and NHPs are analyzed in chronological order, the results reflect advances in the evaluation of a-syn pathology. From searching for differences in protein distribution, to the use of PK pretreatment to differentiate between soluble and insoluble aggregation, the studies do not seem to invalidate each other, but rather build upon each other. The human MPTP morphology should be revisited, keeping in mind that evaluation of a-syn expression beyond LB pathology was not considered. If tissue is available, new studies using different staining strategies, protein or RNA identification and quantification could shed light on this question. The collective data on MPTP-treated monkeys strongly suggest that exposure to this toxin triggers changes in a-syn expression that persists for many years. Aging seems to play a role in the response, increasing the chances of aggregation. When extensive nigral cell loss is found after MPTP dosing, only minimal a-syn pathology is present in the few remaining neurons, probably due to lack of cells to show it. It should be noted that in a-syn knockout mice (Schluter et al., 2003) are partially protected against MPTP, while overexpression of human a-syn A53T (Yu et al., 2008) increases sensitivity to MPTP, although not all SNCA mutations have the same effect (e.g.: A30P, (Rathke-Hartlieb et al., 2001). The collective data supports the concept that asyn has a role in MPTP toxicity (which can be considered an example of environmental insult) without overt LB generation, either because of the rapid cell death, minimal cell survival or because LBs are not the limiting step in MPTP toxicity.

\subsection{Does overexpression of a-syn induce a "true" PD NHP model?}

Accumulation of either normal or mutant a-syn is proposed to lead to protein aggregation and eventually LB formation and cell death. As we mentioned in previous sections, modeling this intracellular buildup of protein has been successfully achieved by injecting viral vectors encoding for SNCA wild type or A53T mutation into the CNS or oocytes. Yet like all models, several caveats should be kept in mind before considering them "true" PD models.

If the model is induced by intracerebral injections of vectors (as well as a-syn formulations or neurotoxins), the effect is mainly found in targeted areas, which is different from widespread CNS and PNS PD pathology. It can be argued that a-syn formulations can propagate a-syn aggregation through the neural networks, yet until now central to peripheral (or vice versa) has not been demonstrated in NHPs. Intracerebral injections also imply that the $\mathrm{BBB}$ is temporarily broken, which should be kept in mind when designing experiments 
testing systemic neuroprotective treatments early after brain surgery. Transgenesis by lentiviral transfection of oocytes, provides an alternative to generate systemic disease, and avoid BBB problems, yet how similar the model is to PD remains to be studied.

The biological rationale for inducing models by a-syn overexpression is that they resemble the rare condition of PD patients carrying duplications or triplications of wild type SNCA. Although human cases with multiplications of the A53T gene have not been reported, models overexpressing A53T have been developed, a fact that needs to be considered when assessing pathology, as well as efficacy of candidate therapies. Furthermore, the impact of the genetic make up of the model organism needs to be taken into account, as, for example, marmoset monkeys have naturally occurring 53T.

SNCA gene multiplications have been associated with earlier disease onset and faster progression than sporadic PD. Duplications and triplications of the SNCA have been found in twenty five patients with autosomal dominant inherited PD belonging to the southern Swedish "Lister family" which are descended from a large kindred characterized by Herman Lundborg in 1901-1913 (Kasten and Klein, 2013). Other family members have shown dementia, dementia praecox and autosomal recessively inherited pediatric disease with nocturnal tonic-clonic fits, subsequent progressive myoclonus, startle reactions, tremor and muscle rigidity. The pediatric myoclonus patients have been historically classified as having progressive myoclonus epilepsy type 1 (EPM1), which is associated with a mutation in the cystatin B gene. As the clinical descriptions of 17 cases within this kindred differ from EPM1, it has been proposed that the pediatric disease, as well as the parkinsonism and dementia phenotypes, are associated with duplications, triplications and possibly higherorder multiplications of the SNCA gene (Puschmann, 2013). This example underscores the potential variability in phenotypes induced by SNCA multiplication, which should be considered when evaluating overexpression models by applying appropriate evaluation tests. It also highlights that a-syn overexpression models are not necessarily "true" PD models but rather useful platforms to understand the impact of a-syn burden.

\subsection{What does inoculation of a-syn formulations model?}

Inoculation of a-syn formulations into the nervous system has been proposed for the study of a-syn pathology and its propagation, and as such they are useful study platforms.

Models generated by inoculation of a-syn formulations share several caveats with intracerebral gene delivery methods (see above) including target limitations and breakage of the BBB. At this point, it is difficult to assess if the induced pathology generates a PD phenotype in NHPs. Although the inoculation of LB extracts is an exciting possibility, it presents other challenges to be considered, including availability, concentration and variability between formulation lots. The latter is the most problematic as, in addition of asyn, 70 different types of molecules have been found in LBs (Wakabayashi et al., 2007) and diversity of donors may affect the composition of the formulation, and therefore replicability of the models. 


\subsection{Conclusions And Future Studies}

Since its discovery, a-syn has been targeted as a prime biomarker of PD pathology. Its investigation in NHP models of PD could prove to be instrumental in developing tools for early diagnoses and strategies to prevent protein aggregation. Although current data on asyn changes in PD NHP models is limited, there are several descriptions of accumulation or variations in a-syn cellular compartmentalization associated with age or MPTP exposure. They suggest that a combination of natural age-related progression of increased intracellular a-syn protein plus a stressful cytotoxic event can lead to pathological changes. a-Syn overexpression studies confirm that protein overload can induce neurodegeneration. Publication of comprehensive studies with a-syn PFFs or LB formulations using appropriate number of NHPs per group are needed before considering them as validated testing platforms. PD stereotypical round LBs with a halo, confirmed by immunostaining with PK pretreatment have not been described in any NHP PD model. Although this is a hindrance when aiming to replicate human PD pathology, lack of LBs may not be necessary for the study of a-syn aggregation. Likewise, this missing element suggests gaps in knowledge that would be beneficial for the PD field to complete.

Better understanding of a-syn changes in NHP models of PD and other PD-like syndromes may help unravel its role in PD pathology and progression. From our analysis possible future strategies to facilitate this process emerge: 1) Evaluation of a-syn expression changes in animal models of PD following basic parameters to allow comparison between reports. 2) Postmortem systematic search for a-syn changes in aged NHPs deceased in captive colonies to create a data bank of changes. 3) Studies on the molecular changes associated with 53T expressing species that could provide clues on interplay between genes. 4) Comparison of the differences between pathology generated by "overexpression" or "overload" versus "regular" expression levels of wild type or mutated a-syn. Research in NHPs is difficult and expensive, as well as invaluable. Authors and journal editors should devote additional efforts to ensure the publication of studies with hypothesis-driven experimental designs, appropriate number of subjects, and blind analysis in order to generate biologically and statistically valid conclusions (Kimmelman et al., 2009; London et al., 2010).

Recent advances in genomic editing are promising for addressing the impact of protein expression levels. A novel method for the generation of genetically modified NHPs is through the utilization of CRISPR/Cas9-mediated genomic editing (Niu et al., 2014b). Although this strategy has not yet been applied to PD genes, its feasibility in NHPs has been demonstrated with other genes. Editing PPAR- $\gamma$ and Rag1 in one-cell-stage embryos using Cas9 mRNA and single guide RNAs (sgRNAs) led to the successful birth of 2 edited cynomolgus monkeys. Tools like this could be instrumental in creating a uni or multi-variant transgenic model that would more accurately reflect the multiple systems affect seen in human PD and allow editing resembling variants between species.

To conclude, PD is complex and has different phenotypic presentations and potential etiologies, which could be matched by the different PD NHP models. It will depend on the investigators to realize their limitations, and match the question to be answered to the most suitable model. 


\section{Acknowledgments}

This research was supported by NIH grants R24 OD019803, P51OD011106 and P51OD011106-53S2 (Wisconsin National Primate Research Center, University of Wisconsin-Madison), NINDS T32-Neuroscience Training Program (S.C.V.), pilot funding from UL1TR000427 (to the Wisconsin Institutes for Clinical and Translational Research) and bridge funding from the UW-Madison Vice Chancellor for Research and Graduate Education. This research was conducted at a facility constructed with support from Research Facilities Improvement Program grants RR15459-01 and RR020141-01. The authors thank J. Shultz and Dr. Bondarenko for immunohistochemical processing of cardiac and colonic tissue.

\section{References}

Alvarez-Fischer D, Henze C, Strenzke C, Westrich J, Ferger B, Hoglinger GU, Oertel WH, Hartmann A. Characterization of the striatal 6-OHDA model of Parkinson's disease in wild type and alphasynuclein-deleted mice. Experimental neurology. 2008; 210:182-193. [PubMed: 18053987]

Bartels T, Choi JG, Selkoe DJ. alpha-Synuclein occurs physiologically as a helically folded tetramer that resists aggregation. Nature. 2011; 477:107-110. [PubMed: 21841800]

Bendor JT, Logan TP, Edwards RH. The function of alpha-synuclein. Neuron. 2013; 79:1044-1066. [PubMed: 24050397]

Betarbet R, Sherer TB, MacKenzie G, Garcia-Osuna M, Panov AV, Greenamyre JT. Chronic systemic pesticide exposure reproduces features of Parkinson's disease. Nature neuroscience. 2000; 3:13011306. [PubMed: 11100151]

Bjorklund A, Kirik D, Rosenblad C, Georgievska B, Lundberg C, Mandel RJ. Towards a neuroprotective gene therapy for Parkinson's disease: use of adenovirus, AAV and lentivirus vectors for gene transfer of GDNF to the nigrostriatal system in the rat Parkinson model. Brain research. 2000; 886:82-98. [PubMed: 11119690]

Blandini F, Armentero MT, Martignoni E. The 6-hydroxydopamine model: news from the past. Parkinsonism \& related disorders. 2008; 14(Suppl 2):S124-S129. [PubMed: 18595767]

Blum D, Torch S, Lambeng N, Nissou M, Benabid AL, Sadoul R, Verna JM. Molecular pathways involved in the neurotoxicity of 6-OHDA, dopamine and MPTP: contribution to the apoptotic theory in Parkinson's disease. Progress in neurobiology. 2001; 65:135-172. [PubMed: 11403877]

Bove J, Zhou C, Jackson-Lewis V, Taylor J, Chu Y, Rideout HJ, Wu DC, Kordower JH, Petrucelli L, Przedborski S. Proteasome inhibition and Parkinson's disease modeling. Annals of neurology. 2006; 60:260-264. [PubMed: 16862585]

Braak H, Braak E, Yilmazer D, Schultz C, de Vos RA, Jansen EN. Nigral and extranigral pathology in Parkinson's disease. Journal of neural transmission Supplementum. 1995; 46:15-31. [PubMed: 8821039]

Braak H, Ghebremedhin E, Rub U, Bratzke H, Del Tredici K. Stages in the development of Parkinson's disease-related pathology. Cell and tissue research. 2004; 318:121-134. [PubMed: 15338272]

Burger C, Gorbatyuk OS, Velardo MJ, Peden CS, Williams P, Zolotukhin S, Reier PJ, Mandel RJ, Muzyczka N. Recombinant AAV viral vectors pseudotyped with viral capsids from serotypes 1, 2, and 5 display differential efficiency and cell tropism after delivery to different regions of the central nervous system. Molecular therapy : the journal of the American Society of Gene Therapy. 2004; 10:302-317. [PubMed: 15294177]

Canron MH, Perret M, Vital A, Bezard E, Dehay B. Age-dependent alpha-synuclein aggregation in the Microcebus murinus lemur primate. Scientific reports. 2012; 2:910. [PubMed: 23205271]

Chandra S, Gallardo G, Fernandez-Chacon R, Schluter OM, Sudhof TC. Alpha-synuclein cooperates with CSPalpha in preventing neurodegeneration. Cell. 2005; 123:383-396. [PubMed: 16269331]

Chaudhuri KR, Odin P. The challenge of non-motor symptoms in Parkinson's disease. Progress in brain research. 2010; 184:325-341. [PubMed: 20887883]

Chaudhuri KR, Odin P, Antonini A, Martinez-Martin P. Parkinson's disease: the non-motor issues. Parkinsonism \& related disorders. 2011; 17:717-723. [PubMed: 21741874] 
Chu Y, Kordower JH. Age-associated increases of alpha-synuclein in monkeys and humans are associated with nigrostriatal dopamine depletion: Is this the target for Parkinson's disease? Neurobiology of disease. 2007; 25:134-149. [PubMed: 17055279]

Chu Y, Kordower JH. The prion hypothesis of Parkinson's disease. Current neurology and neuroscience reports. 2015; 15:28. [PubMed: 25868519]

Conway KA, Lee SJ, Rochet JC, Ding TT, Williamson RE, Lansbury PT Jr. Acceleration of oligomerization, not fibrillization, is a shared property of both alpha-synuclein mutations linked to early-onset Parkinson's disease: implications for pathogenesis and therapy. Proceedings of the National Academy of Sciences of the United States of America. 2000; 97:571-576. [PubMed: 10639120]

Cooper O, Astradsson A, Hallett P, Robertson H, Mendez I, Isacson O. Lack of functional relevance of isolated cell damage in transplants of Parkinson's disease patients. Journal of neurology. 2009; 2563(Suppl):310-316. [PubMed: 19711122]

Dauer W, Przedborski S. Parkinson's disease: mechanisms and models. Neuron. 2003; 39:889-909. [PubMed: 12971891]

Davis GC, Williams AC, Markey SP, Ebert MH, Caine ED, Reichert CM, Kopin IJ. Chronic Parkinsonism secondary to intravenous injection of meperidine analogues. Psychiatry research. 1979; 1:249-254. [PubMed: 298352]

de Lau LM, Breteler MM. Epidemiology of Parkinson's disease. The Lancet Neurology. 2006; 5:525_ 535. [PubMed: 16713924]

Decressac M, Mattsson B, Bjorklund A. Comparison of the behavioural and histological characteristics of the 6-OHDA and alpha-synuclein rat models of Parkinson's disease. Experimental neurology. 2012; 235:306-315. [PubMed: 22394547]

Ebrahimi-Fakhari D, Cantuti-Castelvetri I, Fan Z, Rockenstein E, Masliah E, Hyman BT, McLean PJ, Unni VK. Distinct roles in vivo for the ubiquitin-proteasome system and the autophagy-lysosomal pathway in the degradation of alpha-synuclein. The Journal of neuroscience : the official journal of the Society for Neuroscience. 2011; 31:14508-14520. [PubMed: 21994367]

Emborg ME. Nonhuman primate models of Parkinson's disease. ILAR journal / National Research Council, Institute of Laboratory Animal Resources. 2007; 48:339-355.

Emborg, ME.; Kordower, JH. Aging in nonhuman primates. In: rwin, JME.; Hof, PR., editors. Interdisciplinary topics in gerontology. Basel ; New York: Karger; 2002. p. 102-117.

Emborg ME, Ma SY, Mufson EJ, Levey AI, Taylor MD, Brown WD, Holden JE, Kordower JH. Agerelated declines in nigral neuronal function correlate with motor impairments in rhesus monkeys. The Journal of comparative neurology. 1998; 401:253-265. [PubMed: 9822152]

Eslamboli A, Georgievska B, Ridley RM, Baker HF, Muzyczka N, Burger C, Mandel RJ, Annett L, Kirik D. Continuous low-level glial cell line-derived neurotrophic factor delivery using recombinant adeno-associated viral vectors provides neuroprotection and induces behavioral recovery in a primate model of Parkinson's disease. The Journal of neuroscience : the official journal of the Society for Neuroscience. 2005; 25:769-777. [PubMed: 15673656]

Eslamboli A, Romero-Ramos M, Burger C, Bjorklund T, Muzyczka N, Mandel RJ, Baker H, Ridley RM, Kirik D. Long-term consequences of human alpha-synuclein overexpression in the primate ventral midbrain. Brain. 2007; 130:799-815. [PubMed: 17303591]

Fornai F, Schluter OM, Lenzi P, Gesi M, Ruffoli R, Ferrucci M, Lazzeri G, Busceti CL, Pontarelli F, Battaglia G, et al. Parkinson-like syndrome induced by continuous MPTP infusion: convergent roles of the ubiquitin-proteasome system and alpha-synuclein. Proceedings of the National Academy of Sciences of the United States of America. 2005; 102:3413-3418. [PubMed: 15716361]

Forno LS, Langston JW, DeLanney LE, Irwin I, Ricaurte GA. Locus ceruleus lesions and eosinophilic inclusions in MPTP-treated monkeys. Annals of neurology. 1986; 20:449-455. [PubMed: 3024555]

Fox SH, Brotchie JM. The MPTP-lesioned non-human primate models of Parkinson's disease. Past, present, and future. Progress in brain research. 2010; 184:133-157. [PubMed: 20887873] 
Fujiwara H, Hasegawa M, Dohmae N, Kawashima A, Masliah E, Goldberg MS, Shen J, Takio K, Iwatsubo T. alpha-Synuclein is phosphorylated in synucleinopathy lesions. Nature cell biology. 2002; 4:160-164. [PubMed: 11813001]

Giasson BI, Uryu K, Trojanowski JQ, Lee VM. Mutant and wild type human alpha-synucleins assemble into elongated filaments with distinct morphologies in vitro. The Journal of biological chemistry. 1999; 274:7619-7622. [PubMed: 10075647]

Goldberg AL. Protein degradation and protection against misfolded or damaged proteins. Nature. 2003; 426:895-899. [PubMed: 14685250]

Hallett PJ, Cooper O, Sadi D, Robertson H, Mendez I, Isacson O. Long-term health of dopaminergic neuron transplants in Parkinson's disease patients. Cell reports. 2014; 7:1755-1761. [PubMed: 24910427]

Halliday G, Herrero MT, Murphy K, McCann H, Ros-Bernal F, Barcia C, Mori H, Blesa FJ, Obeso JA. No Lewy pathology in monkeys with over 10 years of severe MPTP Parkinsonism. Movement disorders : official journal of the Movement Disorder Society. 2009; 24:1519-1523. [PubMed: 19526568]

Hamilton BA. alpha-Synuclein A53T substitution associated with Parkinson disease also marks the divergence of Old World and New World primates. Genomics. 2004; 83:739-742. [PubMed: 15028296]

Hilker R, Brotchie JM, Chapman J. Pros and cons of a prion-like pathogenesis in Parkinson's disease. BMC neurology. 2011; 11:74. [PubMed: 21689433]

Irwin DJ, Abrams JY, Schonberger LB, Leschek EW, Mills JL, Lee VM, Trojanowski JQ. Evaluation of potential infectivity of Alzheimer and Parkinson disease proteins in recipients of cadaverderived human growth hormone. JAMA neurology. 2013; 70:462-468. [PubMed: 23380910]

Joers V, Dilley K, Rahman S, Jones C, Shultz J, Simmons H, Emborg ME. Cardiac Sympathetic Denervation in 6-OHDA-Treated Nonhuman Primates. PloS one. 2014a; 9:e104850. [PubMed: 25133405]

Joers V, Emborg ME. Modeling and imaging cardiac sympathetic neurodegeneration in Parkinson's disease. American journal of nuclear medicine and molecular imaging. 2014; 4:125-159. [PubMed: 24753981]

Joers V, Seneczko K, Goecks NC, Kamp TJ, Hacker TA, Brunner KG, Engle JW, Barnhart TE, Nickles RJ, Holden JE, et al. Nonuniform cardiac denervation observed by 11C-metahydroxyephedrine PET in 6-OHDA-treated monkeys. PloS one. 2012; 7:e35371. [PubMed: 22539969]

Joers V, Vermilyea S, Dilley K, Emborg ME. Systemic administration of 6-OHDA to rhesus monkeys upregulates HLA-DR expression in brain microvasculature. Journal of inflammation research. 2014b; 7:139-149. [PubMed: 25258551]

Kalia LV, Lang AE. Parkinson's disease. Lancet. 2015

Kasten M, Klein C. The many faces of alpha-synuclein mutations. Movement disorders : official journal of the Movement Disorder Society. 2013; 28:697-701. [PubMed: 23674458]

Kimmelman J, London AJ, Ravina B, Ramsay T, Bernstein M, Fine A, Stahnisch FW, Emborg ME. Launching invasive, first-in-human trials against Parkinson's disease: ethical considerations. Movement disorders : official journal of the Movement Disorder Society. 2009; 24:1893-1901. [PubMed: 19672990]

Kirik D, Annett LE, Burger C, Muzyczka N, Mandel RJ, Bjorklund A. Nigrostriatal alphasynucleinopathy induced by viral vector-mediated overexpression of human alpha-synuclein: a new primate model of Parkinson's disease. Proceedings of the National Academy of Sciences of the United States of America. 2003; 100:2884-2889. [PubMed: 12601150]

Kirik D, Rosenblad C, Burger C, Lundberg C, Johansen TE, Muzyczka N, Mandel RJ, Bjorklund A. Parkinson-like neurodegeneration induced by targeted overexpression of alpha-synuclein in the nigrostriatal system. The Journal of neuroscience : the official journal of the Society for Neuroscience. 2002; 22:2780-2791. [PubMed: 11923443]

Klein A, Gidyk DC, Shriner AM, Colwell KL, Tatton NA, Tatton WG, Metz GA. Dose-dependent loss of motor function after unilateral medial forebrain bundle rotenone lesion in rats: a cautionary note. Behavioural brain research. 2011; 222:33-42. [PubMed: 21419806] 
Klionsky DJ. Autophagy: from phenomenology to molecular understanding in less than a decade. Nature reviews Molecular cell biology. 2007; 8:931-937. [PubMed: 17712358]

Koprich JB, Johnston TH, Reyes MG, Sun X, Brotchie JM. Expression of human A53T alphasynuclein in the rat substantia nigra using a novel AAV1/2 vector produces a rapidly evolving pathology with protein aggregation, dystrophic neurite architecture and nigrostriatal degeneration with potential to model the pathology of Parkinson's disease. Molecular neurodegeneration. 2010; 5:43. [PubMed: 21029459]

Kordower JH, Chu Y, Hauser RA, Freeman TB, Olanow CW. Lewy body-like pathology in long-term embryonic nigral transplants in Parkinson's disease. Nature medicine. 2008; 14:504-506.

Kordower JH, Kanaan NM, Chu Y, Suresh Babu R, Stansell J 3rd, Terpstra BT, Sortwell CE, SteeceCollier K, Collier TJ. Failure of proteasome inhibitor administration to provide a model of Parkinson's disease in rats and monkeys. Annals of neurology. 2006; 60:264-268. [PubMed: 16862579]

Kowall NW, Hantraye P, Brouillet E, Beal MF, McKee AC, Ferrante RJ. MPTP induces alphasynuclein aggregation in the substantia nigra of baboons. Neuroreport. 2000; 11:211-213. [PubMed: 10683860]

Kruger R, Kuhn W, Muller T, Woitalla D, Graeber M, Kosel S, Przuntek H, Epplen JT, Schols L, Riess O. Ala30Pro mutation in the gene encoding alpha-synuclein in Parkinson's disease. Nature genetics. 1998; 18:106-108. [PubMed: 9462735]

Langston JW. The Parkinson's complex: parkinsonism is just the tip of the iceberg. Annals of neurology. 2006; 59:591-596. [PubMed: 16566021]

Langston JW, Ballard P, Tetrud JW, Irwin I. Chronic Parkinsonism in humans due to a product of meperidine-analog synthesis. Science. 1983; 219:979-980. [PubMed: 6823561]

Langston JW, Forno LS, Tetrud J, Reeves AG, Kaplan JA, Karluk D. Evidence of active nerve cell degeneration in the substantia nigra of humans years after 1-methyl-4-phenyl-1,2,3,6tetrahydropyridine exposure. Annals of neurology. 1999; 46:598-605. [PubMed: 10514096]

Larsen K, Hedegaard C, Bertelsen MF, Bendixen C. Threonine 53 in alpha-synuclein is conserved in long-living non-primate animals. Biochemical and biophysical research communications. 2009; 387:602-605. [PubMed: 19619507]

Leroy E, Boyer R, Auburger G, Leube B, Ulm G, Mezey E, Harta G, Brownstein MJ, Jonnalagada S, Chernova T, et al. The ubiquitin pathway in Parkinson's disease. Nature. 1998; 395:451-452. [PubMed: 9774100]

Lesage S, Anheim M, Letournel F, Bousset L, Honore A, Rozas N, Pieri L, Madiona K, Durr A, Melki $\mathrm{R}$, et al. G51D alpha-synuclein mutation causes a novel parkinsonian-pyramidal syndrome. Annals of neurology. 2013

Li JY, Englund E, Holton JL, Soulet D, Hagell P, Lees AJ, Lashley T, Quinn NP, Rehncrona S, Bjorklund A, et al. Lewy bodies in grafted neurons in subjects with Parkinson's disease suggest host-to-graft disease propagation. Nature medicine. 2008; 14:501-503.

Li JY, Englund E, Widner H, Rehncrona S, Bjorklund A, Lindvall O, Brundin P. Characterization of Lewy body pathology in 12- and 16-year-old intrastriatal mesencephalic grafts surviving in a patient with Parkinson's disease. Movement disorders : official journal of the Movement Disorder Society. 2010; 25:1091-1096. [PubMed: 20198645]

Lindgren HS, Lelos MJ, Dunnett SB. Do alpha-synuclein vector injections provide a better model of Parkinson's disease than the classic 6-hydroxydopamine model? Experimental neurology. 2012; 237:36-42. [PubMed: 22727767]

London AJ, Kimmelman J, Emborg ME. Research ethics. Beyond access vs. protection in trials of innovative therapies. Science. 2010; 328:829-830. [PubMed: 20466907]

Luk KC, Kehm V, Carroll J, Zhang B, O'Brien P, Trojanowski JQ, Lee VM. Pathological alphasynuclein transmission initiates Parkinson-like neurodegeneration in nontransgenic mice. Science. 2012; 338:949-953. [PubMed: 23161999]

Luk KC, Song C, O'Brien P, Stieber A, Branch JR, Brunden KR, Trojanowski JQ, Lee VM. Exogenous alpha-synuclein fibrils seed the formation of Lewy body-like intracellular inclusions in cultured cells. Proceedings of the National Academy of Sciences of the United States of America. 2009; 106:20051-20056. [PubMed: 19892735] 
McCormack AL, Mak SK, Shenasa M, Langston WJ, Forno LS, Di Monte DA. Pathologic modifications of alpha-synuclein in 1-methyl-4-phenyl-1,2,3,6-tetrahydropyridine (MPTP)-treated squirrel monkeys. Journal of neuropathology and experimental neurology. 2008; 67:793-802. [PubMed: 18648323]

McLean PJ, Kawamata H, Ribich S, Hyman BT. Membrane association and protein conformation of alpha-synuclein in intact neurons. Effect of Parkinson's disease-linked mutations. The Journal of biological chemistry. 2000; 275:8812-8816. [PubMed: 10722726]

McNaught KS, Belizaire R, Isacson O, Jenner P, Olanow CW. Altered proteasomal function in sporadic Parkinson's disease. Experimental neurology. 2003; 179:38-46. [PubMed: 12504866]

McNaught KS, Perl DP, Brownell AL, Olanow CW. Systemic exposure to proteasome inhibitors causes a progressive model of Parkinson's disease. Annals of neurology. 2004; 56:149-162. [PubMed: 15236415]

Medina M, Avila J. The role of extracellular Tau in the spreading of neurofibrillary pathology. Frontiers in cellular neuroscience. 2014; 8:113. [PubMed: 24795568]

Mendez I, Vinuela A, Astradsson A, Mukhida K, Hallett P, Robertson H, Tierney T, Holness R, Dagher A, Trojanowski JQ, et al. Dopamine neurons implanted into people with Parkinson's disease survive without pathology for 14 years. Nature medicine. 2008; 14:507-509.

Mori F, Nishie M, Kakita A, Yoshimoto M, Takahashi H, Wakabayashi K. Relationship among alphasynuclein accumulation, dopamine synthesis, and neurodegeneration in Parkinson disease substantia nigra. Journal of neuropathology and experimental neurology. 2006; 65:808-815. [PubMed: 16896314]

Narhi L, Wood SJ, Steavenson S, Jiang Y, Wu GM, Anafi D, Kaufman SA, Martin F, Sitney K, Denis $\mathrm{P}$, et al. Both familial Parkinson's disease mutations accelerate alpha-synuclein aggregation. The Journal of biological chemistry. 1999; 274:9843-9846. [PubMed: 10092675]

Niu Y, Guo X, Chen Y, Wang CE, Gao J, Yang W, Kang Y, Si W, Wang H, Yang SH, et al. Early Parkinson's disease symptoms in alpha-synuclein transgenic monkeys. Human molecular genetics. 2014a

Niu Y, Shen B, Cui Y, Chen Y, Wang J, Wang L, Kang Y, Zhao X, Si W, Li W, et al. Generation of gene-modified cynomolgus monkey via Cas9/RNA-mediated gene targeting in one-cell embryos. Cell. 2014b; 156:836-843. [PubMed: 24486104]

Oueslati A, Fournier M, Lashuel HA. Role of post-translational modifications in modulating the structure, function and toxicity of alpha-synuclein: implications for Parkinson's disease pathogenesis and therapies. Progress in brain research. 2010; 183:115-145. [PubMed: 20696318]

Paleologou KE, Oueslati A, Shakked G, Rospigliosi CC, Kim HY, Lamberto GR, Fernandez CO, Schmid A, Chegini F, Gai WP, et al. Phosphorylation at S87 is enhanced in synucleinopathies, inhibits alpha-synuclein oligomerization, and influences synuclein-membrane interactions. The Journal of neuroscience : the official journal of the Society for Neuroscience. 2010; 30:31843198. [PubMed: 20203178]

Pan-Montojo F, Anichtchik O, Dening Y, Knels L, Pursche S, Jung R, Jackson S, Gille G, Spillantini MG, Reichmann H, et al. Progression of Parkinson's disease pathology is reproduced by intragastric administration of rotenone in mice. PloS one. 2010; 5:e8762. [PubMed: 20098733]

Pan-Montojo F, Schwarz M, Winkler C, Arnhold M, O'Sullivan GA, Pal A, Said J, Marsico G, Verbavatz JM, Rodrigo-Angulo M, et al. Environmental toxins trigger PD-like progression via increased alpha-synuclein release from enteric neurons in mice. Scientific reports. 2012; 2:898. [PubMed: 23205266]

Polymeropoulos MH, Lavedan C, Leroy E, Ide SE, Dehejia A, Dutra A, Pike B, Root H, Rubenstein J, Boyer R, et al. Mutation in the alpha-synuclein gene identified in families with Parkinson's disease. Science. 1997; 276:2045-2047. [PubMed: 9197268]

Postuma RB, Aarsland D, Barone P, Burn DJ, Hawkes CH, Oertel W, Ziemssen T. Identifying prodromal Parkinson's disease: pre-motor disorders in Parkinson's disease. Movement disorders : official journal of the Movement Disorder Society. 2012; 27:617-626. [PubMed: 22508280]

Priyadarshi A, Khuder SA, Schaub EA, Priyadarshi SS. Environmental risk factors and Parkinson's disease: a metaanalysis. Environmental research. 2001; 86:122-127. [PubMed: 11437458] 
Przedborski S, Vila M. MPTP: a review of its mechanisms of neurotoxicity. Clin Neurosci Res. 2001; 1:407-418.

Purisai MG, McCormack AL, Langston WJ, Johnston LC, Di Monte DA. Alpha-synuclein expression in the substantia nigra of MPTP-lesioned non-human primates. Neurobiology of disease. 2005; 20:898-906. [PubMed: 16006134]

Puschmann A. Monogenic Parkinson's disease and parkinsonism: clinical phenotypes and frequencies of known mutations. Parkinsonism \& related disorders. 2013; 19:407-415. [PubMed: 23462481]

Rathke-Hartlieb S, Kahle PJ, Neumann M, Ozmen L, Haid S, Okochi M, Haass C, Schulz JB. Sensitivity to MPTP is not increased in Parkinson's disease-associated mutant alphasynuclein transgenic mice. Journal of neurochemistry. 2001; 77:1181-1184. [PubMed: 11359883]

Recasens A, Dehay B, Bove J, Carballo-Carbajal I, Dovero S, Perez-Villalba A, Fernagut PO, Blesa J, Parent A, Perier C, et al. Lewy body extracts from Parkinson disease brains trigger alphasynuclein pathology and neurodegeneration in mice and monkeys. Annals of neurology. 2014; 75:351-362. [PubMed: 24243558]

Ridley RM, Baker HF, Windle CP, Cummings RM. Very long term studies of the seeding of betaamyloidosis in primates. Journal of neural transmission. 2006; 113:1243-1251. [PubMed: 16362635]

Rott R, Szargel R, Haskin J, Bandopadhyay R, Lees AJ, Shani V, Engelender S. alpha-Synuclein fate is determined by USP9X-regulated monoubiquitination. Proceedings of the National Academy of Sciences of the United States of America. 2011; 108:18666-18671. [PubMed: 22065755]

Schluter OM, Fornai F, Alessandri MG, Takamori S, Geppert M, Jahn R, Sudhof TC. Role of alphasynuclein in 1-methyl-4-phenyl-1,2,3,6-tetrahydropyridine-induced parkinsonism in mice. Neuroscience. 2003; 118:985-1002. [PubMed: 12732244]

Seidel K, Mahlke J, Siswanto S, Kruger R, Heinsen H, Auburger G, Bouzrou M, Grinberg L, Wicht H, Korf HW, et al. The brainstem pathologies of Parkinson's disease and dementia with Lewy bodies. Brain pathology. 2014

Senoh SW, B. Non-enzymatic Conversions of Dopamine to Norepinephrine and Trihydroxyphenethylamines. Journal of the American Chemical Society. 1959; 81:6222-6231.

Shannon KM, Keshavarzian A, Dodiya HB, Jakate S, Kordower JH. Is alpha-synuclein in the colon a biomarker for premotor Parkinson's disease? Evidence from 3 cases. Movement disorders : official journal of the Movement Disorder Society. 2012; 27:716-719. [PubMed: 22550057]

Sherer TB, Kim JH, Betarbet R, Greenamyre JT. Subcutaneous rotenone exposure causes highly selective dopaminergic degeneration and alpha-synuclein aggregation. Experimental neurology. 2003; 179:9-16. [PubMed: 12504863]

Shimura H, Schlossmacher MG, Hattori N, Frosch MP, Trockenbacher A, Schneider R, Mizuno Y, Kosik KS, Selkoe DJ. Ubiquitination of a new form of alpha-synuclein by parkin from human brain: implications for Parkinson's disease. Science. 2001; 293:263-269. [PubMed: 11431533]

Singleton AB, Farrer M, Johnson J, Singleton A, Hague S, Kachergus J, Hulihan M, Peuralinna T, Dutra A, Nussbaum R, et al. alpha-Synuclein locus triplication causes Parkinson's disease. Science. 2003; 302:841. [PubMed: 14593171]

Smith WW, Margolis RL, Li X, Troncoso JC, Lee MK, Dawson VL, Dawson TM, Iwatsubo T, Ross CA. Alpha-synuclein phosphorylation enhances eosinophilic cytoplasmic inclusion formation in SH-SY5Y cells. The Journal of neuroscience : the official journal of the Society for Neuroscience. 2005; 25:5544-5552. [PubMed: 15944382]

Spillantini MG, Crowther RA, Jakes R, Hasegawa M, Goedert M. alpha-Synuclein in filamentous inclusions of Lewy bodies from Parkinson's disease and dementia with lewy bodies. Proceedings of the National Academy of Sciences of the United States of America. 1998; 95:6469-6473. [PubMed: 9600990]

Spillantini MG, Schmidt ML, Lee VM, Trojanowski JQ, Jakes R, Goedert M. Alpha-synuclein in Lewy bodies. Nature. 1997; 388:839-840. [PubMed: 9278044]

Stefanis L, Larsen KE, Rideout HJ, Sulzer D, Greene LA. Expression of A53T mutant but not wildtype alpha-synuclein in PC12 cells induces alterations of the ubiquitin-dependent degradation system, loss of dopamine release, and autophagic cell death. The Journal of neuroscience : the official journal of the Society for Neuroscience. 2001; 21:9549-9560. [PubMed: 11739566] 
Stocchi F, Olanow CW. Obstacles to the development of a neuroprotective therapy for Parkinson's disease. Movement disorders : official journal of the Movement Disorder Society. 2013; 28:3-7. [PubMed: 23390094]

Tran L, Greenwood-Van Meerveld B. In a non-human primate model, aging disrupts the neural control of intestinal smooth muscle contractility in a region-specific manner. Neurogastroenterology and motility : the official journal of the European Gastrointestinal Motility Society. 2014; 26:410418. [PubMed: 24548258]

Ueda K, Fukushima H, Masliah E, Xia Y, Iwai A, Yoshimoto M, Otero DA, Kondo J, Ihara Y, Saitoh T. Molecular cloning of cDNA encoding an unrecognized component of amyloid in Alzheimer disease. Proceedings of the National Academy of Sciences of the United States of America. 1993; 90:11282-11286. [PubMed: 8248242]

Ungerstedt U. 6-Hydroxy-dopamine induced degeneration of central monoamine neurons. European journal of pharmacology. 1968; 5:107-110. [PubMed: 5718510]

Vila M, Vukosavic S, Jackson-Lewis V, Neystat M, Jakowec M, Przedborski S. Alpha-synuclein upregulation in substantia nigra dopaminergic neurons following administration of the parkinsonian toxin MPTP. Journal of neurochemistry. 2000; 74:721-729. [PubMed: 10646524]

Volpicelli-Daley LA, Luk KC, Patel TP, Tanik SA, Riddle DM, Stieber A, Meaney DF, Trojanowski JQ, Lee VM. Exogenous alpha-synuclein fibrils induce Lewy body pathology leading to synaptic dysfunction and neuron death. Neuron. 2011; 72:57-71. [PubMed: 21982369]

Wakabayashi K, Tanji K, Mori F, Takahashi H. The Lewy body in Parkinson's disease: molecules implicated in the formation and degradation of alpha-synuclein aggregates. Neuropathology : official journal of the Japanese Society of Neuropathology. 2007; 27:494-506. [PubMed: 18018486]

Watkin EE, Arbez N, Waldron-Roby E, O'Meally R, Ratovitski T, Cole RN, Ross CA. Phosphorylation of mutant huntingtin at serine 116 modulates neuronal toxicity. PloS one. 2014; 9:e88284. [PubMed: 24505464]

Waxman EA, Giasson BI. Characterization of kinases involved in the phosphorylation of aggregated alpha-synuclein. Journal of neuroscience research. 2011; 89:231-247. [PubMed: 21162130]

Winslow AR, Chen CW, Corrochano S, Acevedo-Arozena A, Gordon DE, Peden AA, Lichtenberg M, Menzies FM, Ravikumar B, Imarisio S, et al. alpha-Synuclein impairs macroautophagy: implications for Parkinson's disease. The Journal of cell biology. 2010; 190:1023-1037. [PubMed: 20855506]

Xilouri M, Brekk OR, Landeck N, Pitychoutis PM, Papasilekas T, Papadopoulou-Daifoti Z, Kirik D, Stefanis L. Boosting chaperone-mediated autophagy in vivo mitigates alpha-synuclein-induced neurodegeneration. Brain. 2013; 136:2130-2146. [PubMed: 23757764]

Yang W, Wang G, Wang CE, Guo X, Yin P, Gao J, Tu Z, Wang Z, Wu J, Hu X, et al. Mutant alphasynuclein causes age-dependent neuropathology in monkey brain. The Journal of neuroscience : the official journal of the Society for Neuroscience. 2015; 35:8345-8358. [PubMed: 26019347]

Yu WH, Matsuoka Y, Sziraki I, Hashim A, Lafrancois J, Sershen H, Duff KE. Increased dopaminergic neuron sensitivity to 1-methyl-4-phenyl-1,2,3,6-tetrahydropyridine (MPTP) in transgenic mice expressing mutant A53T alpha-synuclein. Neurochemical research. 2008; 33:902-911. [PubMed: 17999181]

Zarranz JJ, Alegre J, Gomez-Esteban JC, Lezcano E, Ros R, Ampuero I, Vidal L, Hoenicka J, Rodriguez O, Atares B, et al. The new mutation, E46K, of alpha-synuclein causes Parkinson and Lewy body dementia. Annals of neurology. 2004; 55:164-173. [PubMed: 14755719] 


\section{Highlights}

- a-synuclein accumulation is proposed to have a significant role in Parkinson's disease (PD).

- In this review we critically analyze differences in endogenous $\alpha$-syn, as well as a-syn pathology in PD and current PD NHP models.

- In nonhuman primate models of PD a-synuclein is accumulated or present variations in cellular compartmentalization associated with age or MPTP exposure.

- Overexpression of wild type or mutated a-synuclein in monkeys by viral vector gene transfer induces neurodegeneration.

- A new generation of PD monkey models are being generated using inoculations of a-syn formulations, as well as transgenic methods. 


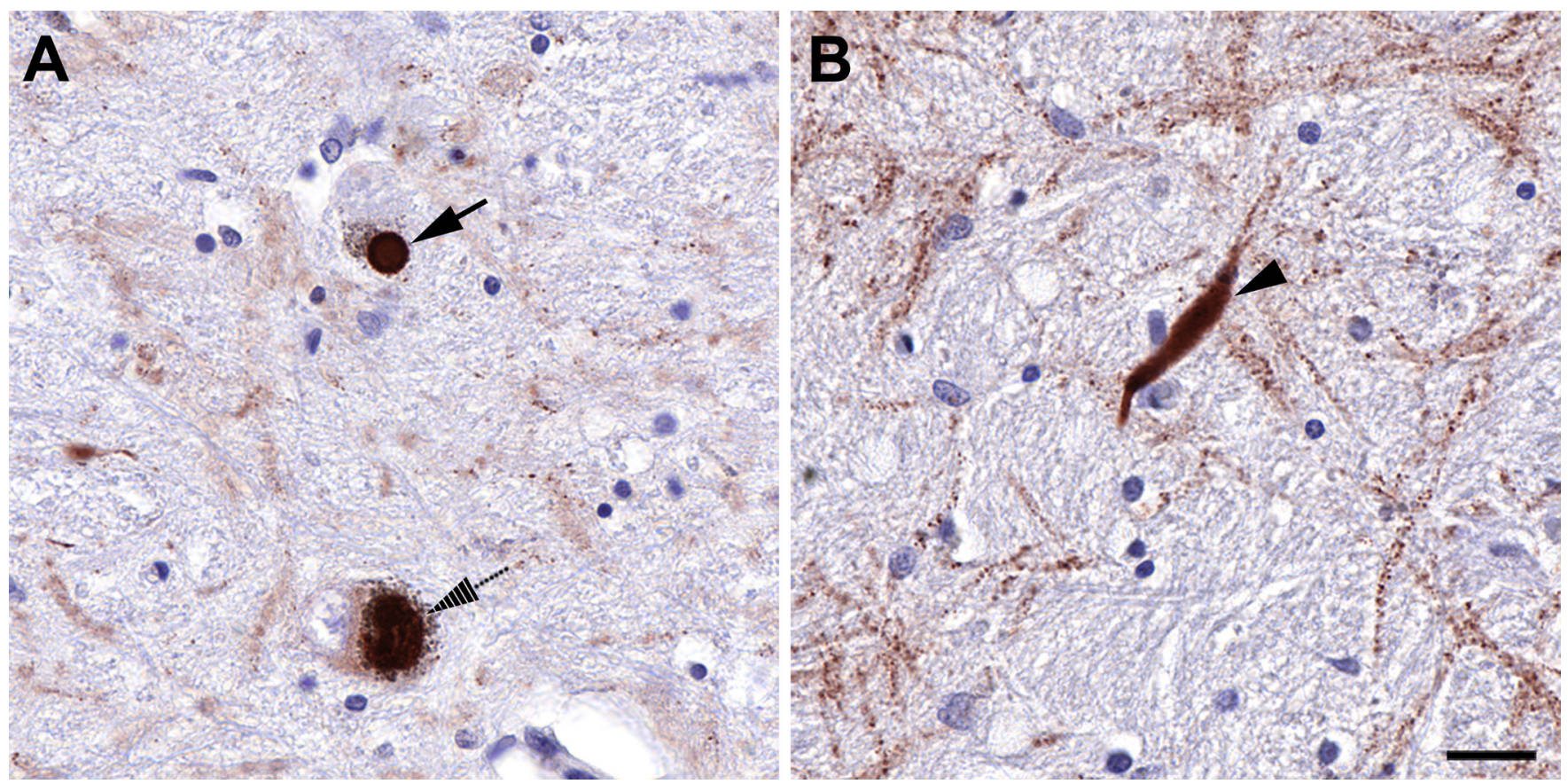

Figure 1. a-Syn is the main component of Lewy bodies (LBs) and Lewy neurites (LNs) Photomicrographs of a human PD brain immunostained against a-syn and counterstained with hematoxylin, showing a typical round LB inclusion (A; arrow), a more amorphous inclusion (A; stripped arrow) and LN (B; arrowhead) in neuromelanin-positive nigral neurons. Scale bar: $25 \mu \mathrm{m}$. 

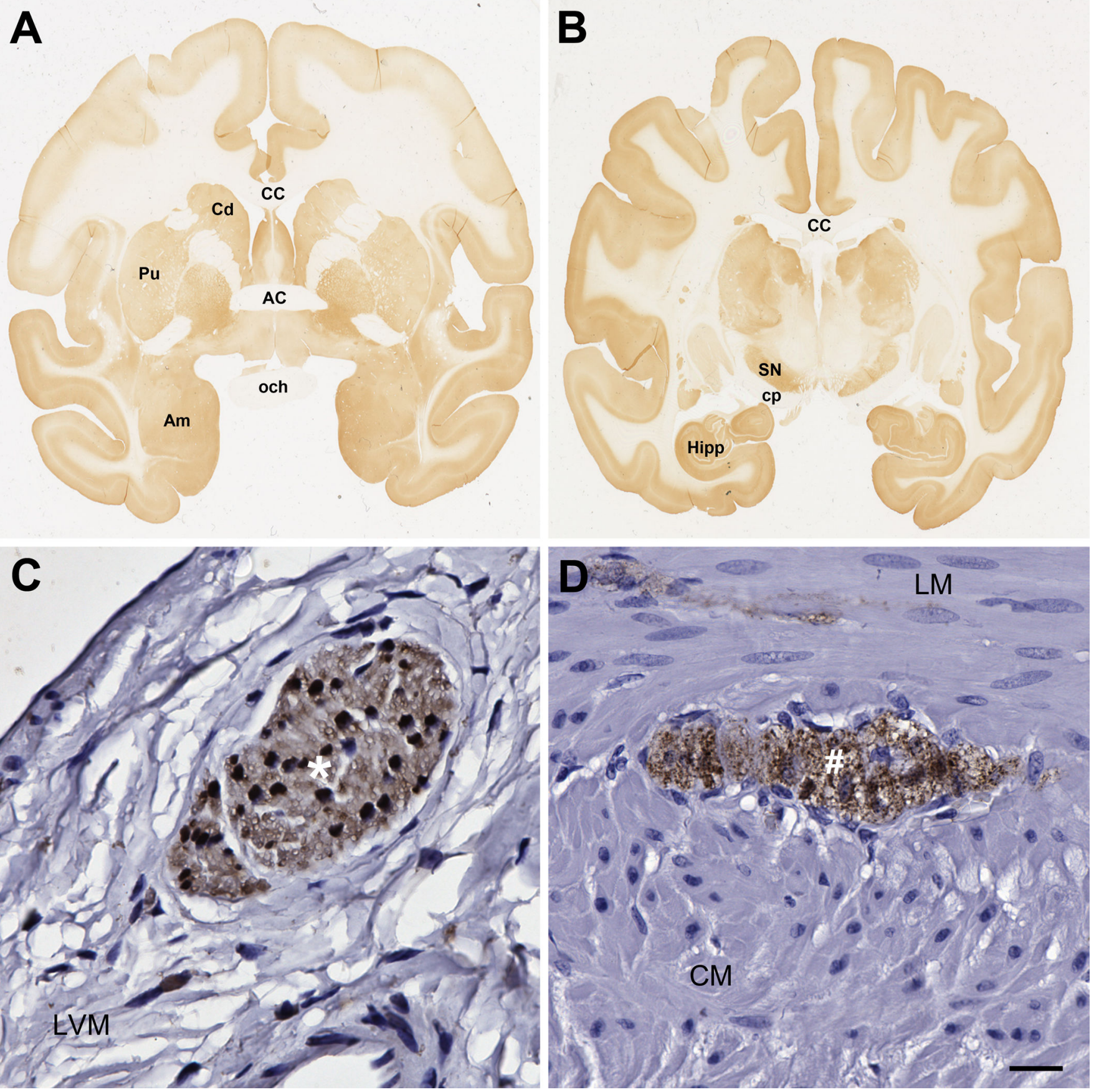

Figure 2.

a-Syn is ubiquitously expressed in the central and peripheral nervous system.

Photomicrographs of coronal brain sections at the level of the anterior commissure (A) and optic chiasm (B), cardiac (C) and proximal colon (D) tissues from rhesus monkeys immunostained against a-syn and counterstained with hematoxylin (C, D). Note the widespread expression of a-syn in brain nuclei and cortex but not in white matter. a-Syn expression is also found in cardiac nerve bundles (*) and colonic enteric ganglion (\#). Abbreviations: AC, anterior commissure; Am, amygdala; $\mathrm{CC}$, corpus callosum; $\mathrm{Cd}$, caudate; 
CM, circular muscle; cp, cerebral peduncle; Hipp, hippocampus; LM, longitudinal muscle; LVM, left ventricular myocardium; och, optic chiasm; Pu, putamen; SN, substantia nigra.

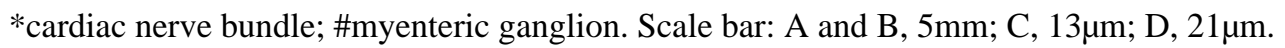


a-Synuclein Amino Acid Residues 0-50

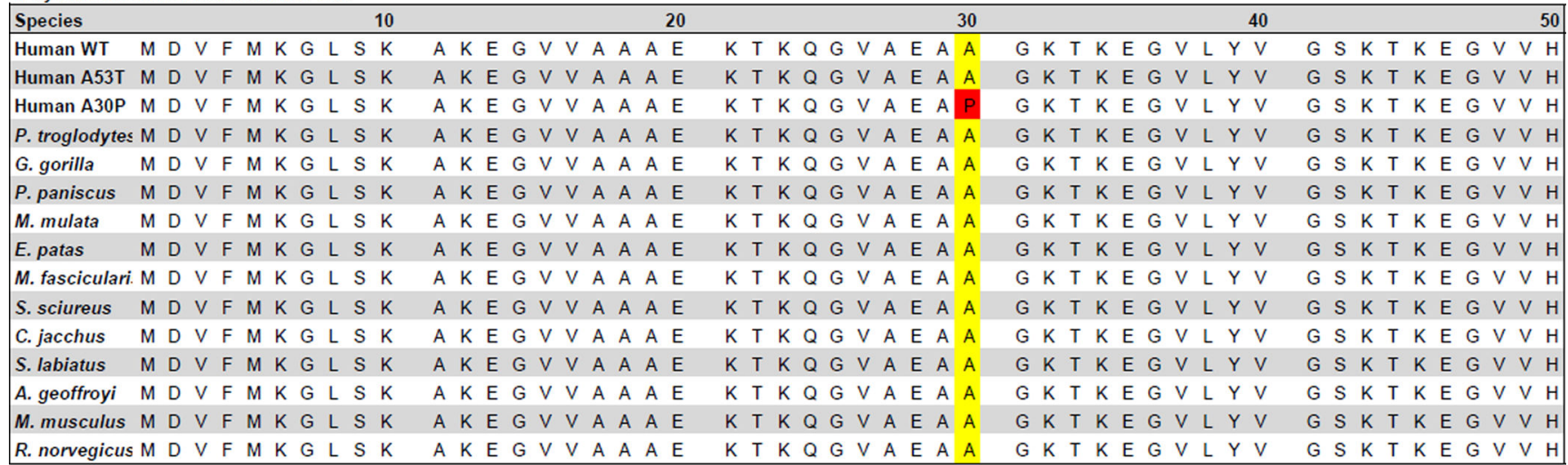

a-Synuclein Amino Acid Residues $51-100$

\begin{tabular}{|c|c|c|c|c|c|c|c|c|c|c|c|c|c|c|c|c|c|c|c|c|c|c|c|c|c|c|c|c|c|c|c|c|c|c|c|c|c|c|c|c|c|c|c|c|c|c|c|}
\hline Species & & & & & & & & & & 60 & & & & & & & & & 70 & & & & & & & & & & 80 & & & & & & & & & 90 & & & & & & & & & 100 \\
\hline Human WT & $G$ & $\mathrm{~V}$ & A & $\mathrm{T}$ & V & A & $E$ & K & $T$ & K & $E$ & $Q$ & V & T & $\mathrm{N}$ & V & G G & $\mathrm{GA}$ & V & V & $\mathrm{T}$ & G & $\mathrm{V}$ & $T$ & A & V & A & $Q$ & $\mathrm{~K}$ & T & $\mathrm{V}$ & $E$ & $\mathrm{G}$ & $A G$ & 5 & E & $\mathrm{A}$ & $\mathrm{A}$ & $A$ & $\mathrm{~T}$ & G & $\mathrm{F}$ & V K & K & $K D$ & $Q$ & $\mathrm{~L}$ \\
\hline Human A53T & G & $\mathrm{v}$ & T & $\mathrm{T}$ & V & A & E & $\mathrm{K}$ & $\begin{array}{l}\mathrm{T} \\
\text {. }\end{array}$ & $\mathrm{K}$ & E & $Q$ & V & $T$ & $\mathrm{~N}$ & V & G G & $\mathrm{A} A$ & V & V & $\mathrm{T}$ & G & V & $\mathrm{T}$ & A & V & A & $Q$ & $\mathrm{~K}$ & T & V & $E$ & $\mathrm{G}$ & $A G$ & 3 & E & $E A$ & $A$ & A & $T$ & G & $\mathrm{F}$ & $V K$ & K & $K D$ & $Q$ & $\mathrm{~L}$ \\
\hline Human $\mathrm{A} 30 \mathrm{P}$ & G & v & A & $T$ & V & A & E & K & $T$ & $\mathrm{~K}$ & E & $Q$ & v & $T$ & $\mathrm{~N}$ & V & $G G$ & $\mathrm{GA}$ & V & V & $\mathrm{T}$ & G & V & $\mathrm{T}$ & A & V & A & $Q$ & K & $\mathrm{T}$ & V & $E$ & $\mathrm{G}$ & $A G$ & 5 & $E$ & $E A$ & A & A & $T$ & G & $\mathrm{F}$ & $\mathrm{V} \mathrm{K}$ & K & $K D$ & $Q$ & $\mathrm{~L}$ \\
\hline P. troglodytes & G & V & A & $\mathrm{T}$ & V & A & E & $\mathrm{K}$ & $\mathrm{T}$ & $\mathrm{K}$ & $E$ & $Q$ & v & T & $\mathrm{N}$ & V & G G & $G \mathrm{~A}$ & V & V & $\mathrm{T}$ & G & V & $\mathrm{T}$ & A & V & A & $Q$ & K & $T$ & V & $E$ & $\mathrm{G}$ & $A G$ & 5 & & $E A$ & A & A & $T$ & G & $\mathrm{F}$ & & K & $K D$ & $Q$ & $\mathrm{~L}$ \\
\hline G. gorilla & G & v & A & $\mathrm{T}$ & V & A & E & K & $T$ & K & $E$ & Q & V & $\mathrm{T}$ & $\mathrm{N}$ & V & G G & $\mathrm{GA}$ & V & V & $\mathrm{T}$ & G & V & $\mathrm{T}$ & A & V & A & $Q$ & $\mathrm{~K}$ & $\mathrm{~T}$ & V & $E$ & G & $A G$ & 3 & E & $E \mathrm{~A}$ & A & A & $\mathrm{T}$ & G & $\mathrm{F}$ & V & K & $K D$ & $Q$ & L \\
\hline P. paniscus & G & V & A & 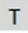 & V & A & E & $\mathrm{K}$ & $T$ & $\mathrm{~K}$ & E & $Q$ & V & $T$ & $\mathrm{~N}$ & V & $G G$ & $G \mathrm{~A}$ & V & V & $T$ & G & V & $T$ & A & V & A & $Q$ & K & T & V & $E$ & G & $A G$ & s & $E$ & $E A$ & A & A & $T$ & G & $\mathrm{F}$ & V & k & $K D$ & $Q$ & $\mathrm{~L}$ \\
\hline M. mulata & G & V & A & $\mathrm{T}$ & V & A & $\mathrm{E}$ & $\mathrm{K}$ & $\mathrm{T}$ & K & $E$ & Q & v & $\mathrm{T}$ & $\mathrm{N}$ & V & G G & $3 \mathrm{~A}$ & V & V & $\mathrm{T}$ & G & V & $\mathrm{T}$ & A & V & A & $Q$ & K & T & V & $E$ & $\mathrm{G}$ & $A G$ & S & $E$ & $E A$ & $A$ & A & $\mathrm{T}$ & G & $\mathrm{F}$ & I & K & $K D$ & $Q$ & $\mathrm{~L}$ \\
\hline E. patas & $G$ & v & $A$ & $T$ & V & A & E & $K$ & $T$ & $\mathrm{~K}$ & $E$ & $Q$ & v & $T$ & $\mathrm{~N}$ & V & G G & $G \mathrm{~A}$ & V & V & $T$ & G & V & $T$ & A & V & A & $Q$ & K & $\begin{array}{l}T \\
\end{array}$ & V & $E$ & G & $A G$ & 3 & E & $E A$ & A & A & $T$ & $G$ & $\mathrm{~F}$ & I & K & $K D$ & $Q$ & $\mathrm{~L}$ \\
\hline M. fasciculari. & $G$ & v & A & $\mathrm{T}$ & V & A & E & K & $\mathrm{T}$ & K & $E$ & Q & V & $T$ & $\mathrm{~N}$ & V & G G & $\mathrm{G}$ & V & V & $\mathrm{T}$ & G & V & $\mathrm{T}$ & A & V & A & $Q$ & K & T & V & $E$ & G & $A G$ & S & & $E A$ & A & A & $\mathrm{T}$ & G & $\mathrm{F}$ & $V \mathrm{~K}$ & K & $K D$ & Q & $\mathrm{L}$ \\
\hline S. sciureus & G & & A & $T$ & V & A & E & $\mathrm{K}$ & $T$ & $\mathrm{~K}$ & E & $Q$ & V & $T$ & $\mathrm{~N}$ & v & G G & $\mathrm{A}$ & V & V & $T$ & G & V & $T$ & A & V & A & $Q$ & $\mathrm{~K}$ & T & V & $E$ & G & $A G$ & & & $E A$ & A & A & $\mathrm{T}$ & G & $\mathrm{F}$ & $\mathrm{V} \mathrm{K}$ & k & $K D$ & 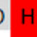 & L \\
\hline C. jacchus & G & & & $\mathrm{T}$ & V & A & E & $\mathrm{K}$ & $\mathrm{T}$ & $\mathrm{K}$ & $E$ & & V & T & $\mathrm{N}$ & V & G G & $G \mathrm{~A}$ & V & V & $\mathrm{T}$ & G & V & $\mathrm{T}$ & A & V & A & $Q$ & $\mathrm{~K}$ & $T$ & V & $E$ & $\mathrm{G}$ & A $G$ & & & $E A$ & $\mathrm{~A}$ & A & $\mathrm{T}$ & G & $\mathrm{F}$ & V K & K & $K D$ & $\mathrm{H}$ & \\
\hline S. labiatus & G & & & $T$ & V & A & E & K & $T$ & $\mathrm{~K}$ & $\mathrm{E}$ & Q & V & $T$ & $\mathrm{~N}$ & V & $G G$ & $\mathrm{GA}$ & V & V & $T$ & G & V & $T$ & A & V & A & $Q$ & $\mathrm{~K}$ & T & V & $E$ & G & $A G$ & & & E A & A & A & $T$ & G & $\mathrm{F}$ & $V R$ & R & K & $Q$ & L \\
\hline A. geoffroyi & G & & & $\mathrm{T}$ & V & A & E & $\mathrm{K}$ & $T$ & $\mathrm{~K}$ & E & & V & $\mathrm{T}$ & S & v & G G & $3 \mathrm{~A}$ & V & V & $\mathrm{T}$ & G & V & $\mathrm{T}$ & A & V & A & $Q$ & $\mathrm{~K}$ & $\mathrm{~T}$ & V & $E$ & G & $A G$ & & & E A & A & A & $\mathrm{T}$ & G & $\mathrm{F}$ & $\mathrm{V} \mathrm{K}$ & K & $K D$ & $Q$ & \\
\hline M. musculus & G & & & $\mathrm{T}$ & V & A & E & K & $\mathrm{T}$ & $\mathrm{K}$ & E & & V & $T$ & $\mathrm{~N}$ & v & G G & $\mathrm{G} A$ & V & V & $\mathrm{T}$ & G & V & $\mathrm{T}$ & A & V & A & $Q$ & $\mathrm{~K}$ & T & V & $E$ & $\mathrm{G}$ & $A$ G & & & E A & $A$ & A & $\mathrm{T}$ & G & $\mathrm{F}$ & V K & K & $K D$ & $Q$ & \\
\hline R. norvegicus & G & $\mathrm{V}$ & & $\mathrm{T}$ & $\mathrm{V}$ & A & $\mathrm{E}$ & $\mathrm{K}$ & $\mathrm{T}$ & $\mathrm{K}$ & $\mathrm{E}$ & Q & V & $\mathrm{T}$ & $\mathrm{N}$ & $\mathrm{V}$ & G G & $3 \mathrm{~A}$ & $\mathrm{~V}$ & V & $\mathrm{T}$ & G & V & $\mathrm{T}$ & A & V & A & Q & $\mathrm{K}$ & T & V & $E$ & G & A G & 3 & & E A & A & A & $\mathrm{T}$ & G & $\mathrm{F}$ & V K & $\mathrm{K}$ & 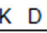 & $Q$ & \\
\hline
\end{tabular}

a-Synuclein Amino Acid Residues 101-140

Species 110

Human WT GK N E E G A P Q E Human A53T G K N E E G A P Q E Human A30P G K N E E G A P Q E P. troglodytes $G K N$ E E G A P Q E $\begin{array}{llllllll}\text { G. gorilla } & G & K & N & E & G & A & P \\ P\end{array}$ P. paniscus $\mathrm{G} K \mathrm{~N}$ E E G A P Q E M. mulata $G \mathrm{~K} N \mathrm{~N} E \mathrm{G}$ A P Q E E. patas $\quad G K N E$ N $G$ A P Q E M. fasciculari $G K N E$ E $G A P Q E$ S. sciureus $G K$ S E E G A P Q E C. jacchus $G K$ S E E G A P Q E s. labiatus $G K S E E G A P Q E$ A. geoffroyi $G K$ S E E G A P Q E M. musculus $\mathrm{G} \mathrm{K}$ R. norvegicus $\mathrm{G} K \mathrm{~K}$ E E G Y P Q E

\begin{tabular}{|c|c|c|c|c|c|c|c|c|c|}
\hline & & & & & & \multicolumn{4}{|c|}{120} \\
\hline G & I & $\mathrm{L}$ & $\mathrm{E}$ & D & M & $P$ & $V$ & & $P$ \\
\hline G & I & $\mathrm{L}$ & $E$ & D & M & $P$ & $V$ & D & $P$ \\
\hline G & I & L & $E$ & D & M & $P$ & V & D & $P$ \\
\hline G & I & L & $E$ & D & M & $P$ & V & D & $P$ \\
\hline G & I & L & $E$ & D & M & $P$ & $V$ & D & $P$ \\
\hline G & I & $\mathrm{L}$ & $\mathrm{E}$ & D & M & $P$ & $V$ & D & $P$ \\
\hline G & I & L & ก & D & M & $P$ & $V$ & D & $P$ \\
\hline G & I & L & ก & D & M & $P$ & V & D & $P$ \\
\hline G & I & L & Q & D & M & $P$ & V & D & $P$ \\
\hline G & I & L & $E$ & D & M & $P$ & V & D & $P$ \\
\hline G & I & L & $E$ & D & M & $P$ & V & D & $P$ \\
\hline G & I & L & $\mathrm{E}$ & D & M & $P$ & V & D & $P$ \\
\hline G & I & L & $E$ & D & M & $P$ & V & D & $P$ \\
\hline G & I & $\mathrm{L}$ & $E$ & D & $M$ & $P$ & V & D & $P$ \\
\hline G & I & L & $E$ & D & & $P$ & V & D & $P$ \\
\hline
\end{tabular}

\begin{tabular}{|c|c|c|c|c|c|c|c|c|c|c|c|c|c|c|c|}
\hline \multicolumn{14}{|c|}{130} & \multicolumn{2}{|c|}{140} \\
\hline D N & E & $A$ & & & $M P$ & $S$ & $E$ & & c & Y & $c$ & D & $Y E P$ & $P E$ & $A$ \\
\hline $\mathrm{DN}$ & $E$ & A & & E & $M P$ & S & $E$ & $E$ & $c$ & $y$ & 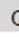 & - & $Y E P$ & $P E$ & A \\
\hline D N & E & A & & b & $M P$ & $\mathrm{~s}$ & E & $E$ & ( & $Y$ & C & [ & $Y E P$ & $P E$ & A \\
\hline $\mathrm{N}$ & E & A & & t & $M P$ & $\mathrm{~s}$ & 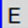 & $\mathrm{E}$ & c & $Y$ & C & D & $Y \in P$ & $P E$ & A \\
\hline D N & $\mathrm{E}$ & A & & B & $M P$ & s & t & $\mathrm{E}$ & 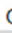 & $Y$ & ( & D & $Y E P$ & $P E$ & A \\
\hline D N & E & & & $\mathrm{B}$ & $M P$ & s & 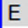 & $\mathrm{E}$ & c & $Y$ & $c$ & D & $Y \in P$ & $P E$ & A \\
\hline D N & E & $A$ & & E & $M P$ & $\mathrm{~s}$ & & & & $Y$ & c & D & $Y E P$ & $P E$ & A \\
\hline D N & E & $A$ & & e & $M P$ & $\mathrm{~s}$ & & & & & 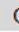 & ח & $Y \in P$ & $P E$ & A \\
\hline D N & E & $A$ & & 1 & $M P$ & $\mathrm{~S}$ & & $E$ & & & c & [ & $Y \in P$ & $P E$ & A \\
\hline D N & E & $A$ & & $\mathrm{E}$ & $M P$ & $\mathrm{~S}$ & $E$ & E & ( & $Y$ & ( & c & $Y E P$ & $P E$ & A \\
\hline D N & E & $A$ & & 1 & $M P$ & $\mathrm{~s}$ & & $E$ & ( & Y & ( & D & $Y E P$ & $P E$ & A \\
\hline D N & E & $A$ & & t & $M P$ & $\mathrm{~s}$ & & E & ( & $Y$ & ( & [ & $Y \in P$ & $P E$ & A \\
\hline D N & E & A & & t & $M P$ & $\mathrm{~s}$ & & $\mathrm{E}$ & & & ( & D & $Y \in P$ & $P E$ & $A$ \\
\hline G S & E & A & & ( & $M P$ & & 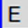 & $E$ & ( & Y & ( & [ & $Y \in P$ & $P E$ & $A$ \\
\hline$s$ & & $A$ & & 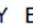 & $M P$ & & & & & & & & $Y E P$ & & \\
\hline
\end{tabular}

\section{0}

\section{.}

Amino acid deviations from human WT

Columns that contain deviations

\section{Figure 3.}

a-Syn has a 140 amino acid sequence that is highly conserved in humans, nonhuman primates, and rodents. Color represents amino acid variation (red) compared to human wild type (WT) sequence (yellow). Note that most new world primates as well as most all other vertebrates have a natural 53T locus, whereas in humans, the A53T mutation leads to an aggressive early onset PD pathology. The serine 129 (S129) phosphorylation site is shown as a blue box. 


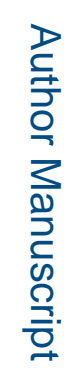

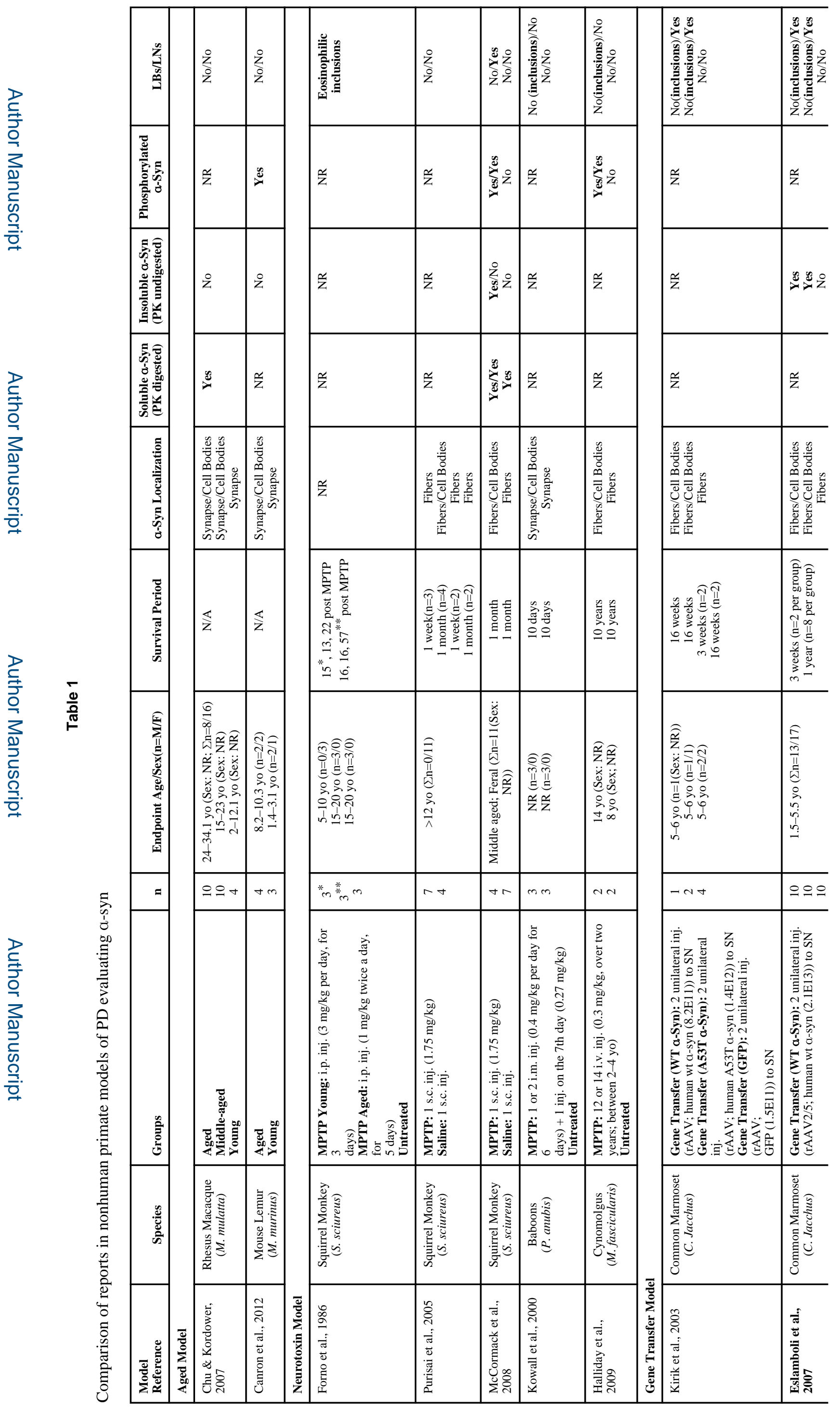

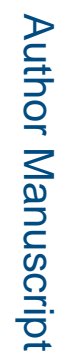




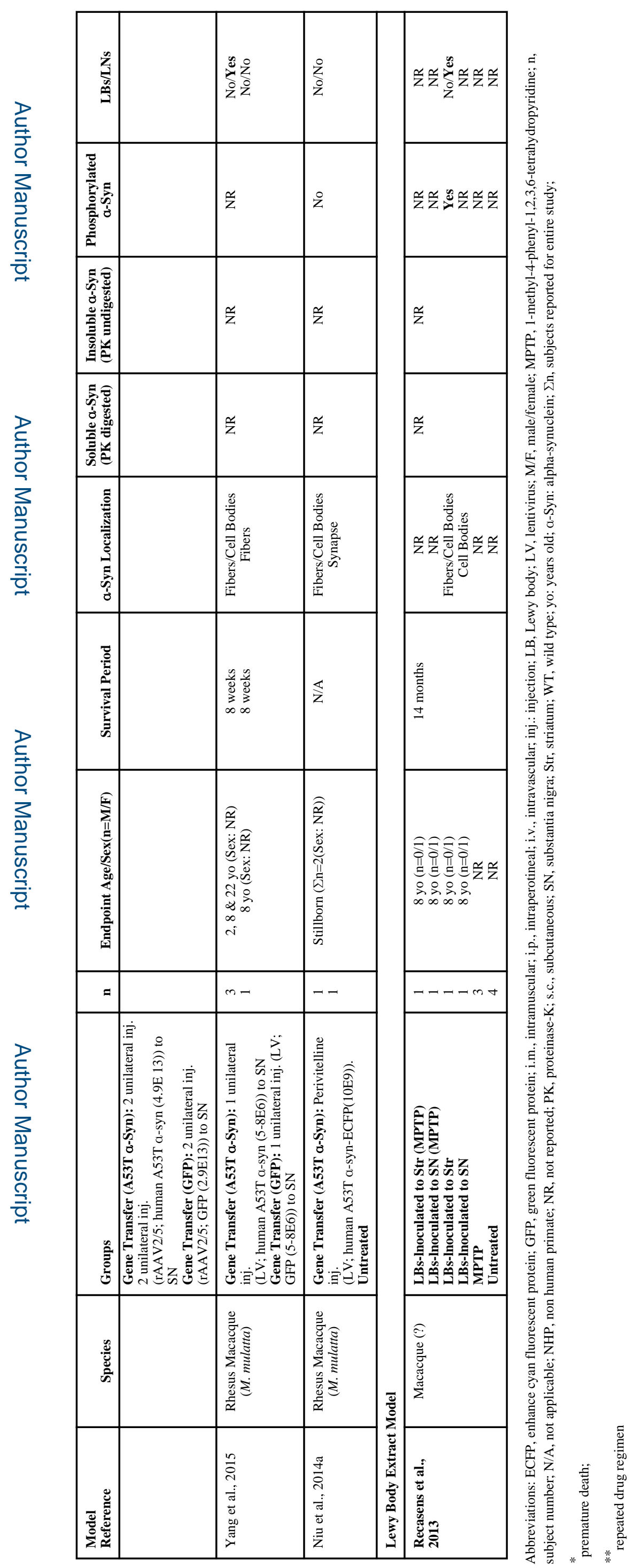

